NASA/TM-1998-207426

$\mathrm{N}+\mathrm{SA}$

Simulated Solar Flare X-Ray and

Thermal Cycling Durability Evaluation of Hubble Space Telescope Thermal Control Candidate Replacement Materials

Kim K. de Groh and Bruce A. Banks

Lewis Research Center, Cleveland, Ohio

Edward A. Sechkar and David A. Scheiman

NYMA, Inc., Brook Park, Ohio

Prepared for the

Fourth International Space Conference on Protection of Materials and Structures from the LEO Space Environment sponsored by the University of Toronto and the Institute for Aerospace Studies Toronto, Canada, April 23-24, 1998

National Aeronautics and

Space Administration

Lewis Research Center 


\section{Acknowledgments}

The authors would like to thank the following for their contributions to this program: Tom Stueber of NYMA Inc., and Alice Jalics of Cleveland State University for tensile tests, Kevin Malinowski of Cleveland State University for assistance with thermal cycling, and Dr. Steven Pepper of NASA Lewis Research Center for $x$-ray spectrum characterization. We would also like to thank Patti Hansen (the HST MLI FRB Chair) and Jacki Townsend of NASA Goddard Space Flight Center, and Joyce Dever of NASA Lewis Research Center for helpful discussions.

Trade names or manufacturers' names : ire used in this report for identification only. This usage does $n \rightarrow t$ constitute an official endorsement, either expressed or implied, by the National Aeronautics and Space Adininistration.

NASA Center for Aerospace Information

7121 Standard Drive

Hanover, MD 21076

Price Code: A03
National Technical Information Service 5285 Port Royal Road Springfield, VA 22100 Price Code: $\mathrm{A} 03$ 


\title{
SIMULATED SOLAR FLARE X-RAY AND THERMAL CYCLING DURABILITY EVALUATION OF HUBBLE SPACE TELESCOPE THERMAL CONTROL CANDIDATE REPLACEMENT MATERIALS
}

\author{
Kim K. de Groh and Bruce A. Banks \\ National Aeronautics and Space Administration \\ Lewis Research Center \\ Cleveland, Ohio 44135 \\ Edward A. Sechkar and David A. Scheiman \\ NYMA, Inc. \\ Brook Park, Ohio 44142
}

During the Hubble Space Telescope (HST) second servicing mission (SM2), astronauts noticed that the multi-layer insulation (MLI) covering the telescope was damaged. Large pieces of the outer layer of MLI (aluminized Teflon ${ }^{\circledR}$ fluorinated ethylene propylene (Al-FEP)) were cracked in several locations around the telescope. A piece of curled up AlFEP was retrieved by the astronauts and was found to be severely embrittled, as witnessed by ground testing. The National Aeronautics and Space Administration (NASA) Goddard Space Flight Center (GSFC) organized a HST MLI Failure Review Board (FRB) to determine the damage mechanism of the Al-FEP in the HST environment, and to recommend a replacement thermal control outer layer material to be installed on HST during the subsequent servicing missions. Candidate thermal control replacement materials were chosen by the FRB and tested for environmental durability under various exposures and durations by GSFC and NASA Lewis Research Center (LeRC). This paper describes durability testing at LeRC of candidate materials which were exposed to charged particle radiation, simulated solar flare $\mathrm{x}$-ray radiation and thermal cycling under load. Samples were evaluated for changes in solar absorptance and tear resistance. Descriptions of environmental exposures and durability evaluations of these materials are presented.

\section{Introduction}

The Hubble Space Telescope (HST) was launched on April 25, 1990 into low Earth orbit and is the first mission of NASA's Great Observatories program. It is a telescope capable of performing observations in the near-ultraviolet, visible and near-infrared $(0.115$ to $1000 \mu \mathrm{m})$. The HST was designed to be serviced on-orbit to upgrade scientific capabilities. The first servicing mission (SM1) occurred in December 1993, after 3.6 years in 
space. The second servicing mission (SM2) was in February 1997, after 6.8 years in space. Servicing missions are planned for mid 2000 and early 2003. ${ }^{1}$

The HST is covered with two types of thermal control materials, radiators and multilayer insulation (MLI) blankets, which passively control temperatures on-orbit. Both of these thermal control materials have metallized-FEF' as the exterior layer. During SM1 astronauts retrieved and returned Al-FEP and Ag-FEP MLI blanket material. The Al-FEP ( 2 blankets retrieved) covered the two magnetometers, and the Ag-FEP MLI covered the solar array drive arm (SADA). Analysis of the retrieved blanket materials revealed that the FEP exterior layer was embrittled on high solar exposure surfaces. ${ }^{2,3}$ Surfaces which received the highest solar exposures ( 16,670 equivalent sun hours (ESH) for the Al-FEP, and 20,056 ESH for the Ag-FEP) had some small through-thickness cracks in the 5 mil FEP at stress locations. 2.3 Solar facing bonded 2 mil Al-FEP on the SADA power harness, which was also retrieved, had many cracks and had lost total mechanical integrity (pulverization). ${ }^{4}$

During SM2, severe cracking of the MLI outer layer material was observed on the Light Shield (LS), Forward Shell (FS) and Equipment Bays of the telescope. Astronaut observations combined with photographic documentation of HST taken during SM2 has revealed extensive cracking of the MLI in many locations around the telescope, with solar facing surfaces being particularly damaged. ${ }^{1}$ The MLI outer layer at several of the longest cracks was observed to be curled up and lifted away from the next MLI layer. Figure 1 shows severely degraded MLI on HST as photographed during SM2.

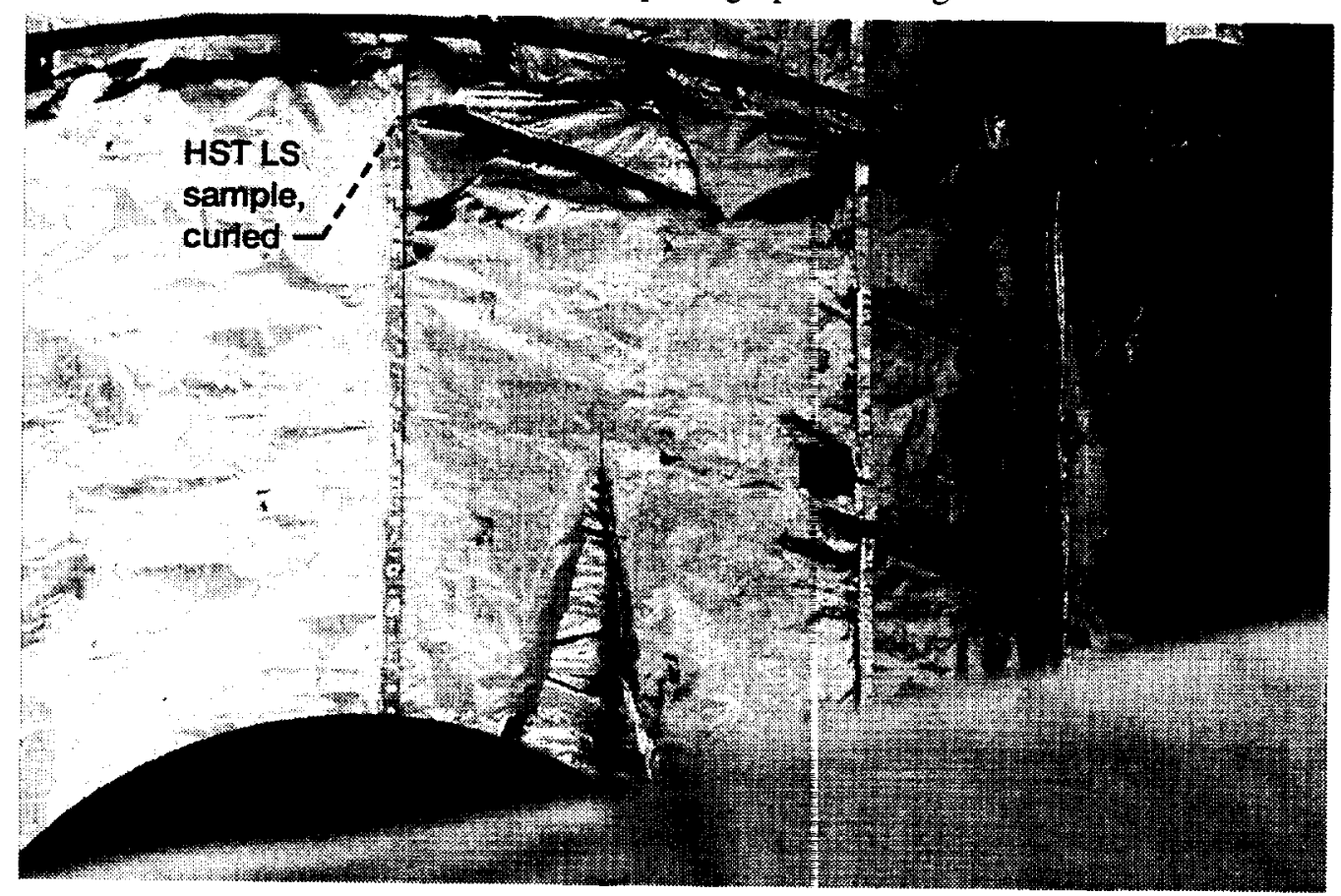

Figure 1. Extensive tearing/curling damage to MLI exterior layer or: HST as photographed during SM2. The tightly curled-up piece was cut off by an astronaut and retrieved for analysis (SM2 LS sample) prior to patching the area. 
The worst of the MLI outer layer cracks were patched during the last EVA (extravehicular activity) day. Contingency patches were placed over the cracks on the light shield, Bay 8 and Bay 10. Due to limited material, Lanyards were used on Bay 7 to hold the cracked MLI in place. Prior to patching the upper light shield crack, the tightly curled outer layer was removed and retrieved for post-mission analysis (see Figure 1). After SM2, GSFC established a HST MLI Failure Review Board (FRB) to determine the cause of degradation of the FEP MLI on HST, and to identify a replacement material to be installed during subsequent servicing missions. Extensive investigation of the optical, chemical and mechanical properties of the retrieved SM2 FEP have been conducted and compared with SMI and pristine FEP results. ${ }^{1.5 .6}$ Simulated LEO environmental exposure testing of pristine FEP was also conducted to help determine the cause of degradation of FEP on HST. ${ }^{7.8}$

The replacement thermal control material was required to meet HST's stringent thermal requirements (end-of-life $\alpha_{\mathrm{s}} / \varepsilon \leq 0.28$ ) and to maintain its structural integrity for at least 10 years on-orbit. Candidate replacement materials were chosen and various sets of materials were exposed to combinations of electron/proton radiation, atomic oxygen, simulated solar flare $x$-rays, thermal cycling and near ultraviolet (NUV) radiation at various facilities in order to evaluate their LEO durability. A summary of all the sets of candidate materials has been written by Townsend et. al. ${ }^{9}$ The simulated solar flare $\mathrm{x}$-ray and thermal cycling exposure testing which was conducted at NASA Lewis Research Center (LeRC) is discussed in this paper.

\section{Materials and Experimental Procedures}

\section{I CANIDIIDATE MATERIALS}

The HST MILI FRB members suggested and considered seventeen replacement thermal control maltcrial. Each replacement material was scored using a multiplicative evaluation formula hased on nine performance criteria chosen by the board. ${ }^{9}$ Six candidate materials were chosen from the list of seventeen for environmental durability testing (materials 1-6). Because of the wringent thermal requirements (end-of-life $\alpha_{s} / \varepsilon \leq 0.28$ ) replacement choices were limiled. Several types of metallized FEP bonded to scrim were chosen because of their excillent optical properties, and because the radiator surfaces on HST (bonded FEP, as opposed in blanket material) maintained their structural integrity as documented during SM2." Four additional materials were also chosen for testing: the current Al-FEP MLI material (matcrial 8 ) to be used to verify environmental damage as witnessed on HST, an Optical Couting Laboratory, Inc. (OCLI) coated sample (material 7) because it is used on some HST exterior surfaces and HST management wanted to check its performance, and two materials ( 9 and 10) chosen by the FRB Chair which were fundamentally different than the first six materials. ${ }^{9}$ These ten materials are listed in Table 1. Materials 3, 4 and 6 (vacuum deposited $\mathrm{Al}$ ) were purchased from Dunmore, who used their proprietary nonUV-darkening polyester adhesive. Materials 1, 2 and 5 (silver/Inconel) were purchased from Sheldahl, who used their proprietary non-UV-darkening polyester adhesive. Material 7 came from GSFC stock, material 8 was supplied by Lockheed Martin Missiles and Space, material 9 was fabricated at GSFC, and material 10 was provided by AZTechnology. ${ }^{9}$ 
Table 1. HST Thermal Control Candidate Replacement Materials

\begin{tabular}{|c|c|c|}
\hline Material & Sample Id. & Candidate Material \\
\hline 1 & $\mathrm{~B} 1.1$ and $\mathrm{M} 2.1$ & 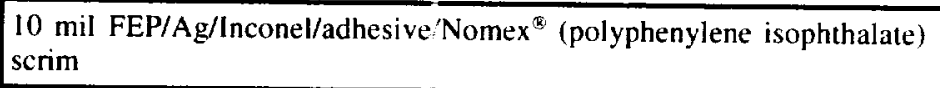 \\
\hline 2 & $\mathrm{~B} 1.2$ and $\mathrm{M} 2.2$ & 5 mil FEP/Ag/Inconel/adhesive/fiberglass scrim/adhesive/2 mil Kapton ${ }^{*}$ \\
\hline 3 & $\mathrm{~B} 1.3$ and $\mathrm{M} 2.3$ & $10 \mathrm{mil} \mathrm{FEP/Al/adhesive/Nomex}{ }^{(6)}$ scrim \\
\hline 4 & $B 1.4$ and $\mathrm{M} 2.4$ & 5 mil FEP/A //adhesive/fiberglass scrim/adhesive/2 mil Kapton ${ }^{\infty}$ \\
\hline 5 & B 1.5 and $M 2.5$ & 5 mil FEP/Ag/Inconel/adhesive/Nomex scrim \\
\hline 6 & $\mathrm{~B} 1.6$ and $\mathrm{M} 2.6$ & 5 mil FEP/A 1/adhesive/Nomex scrim \\
\hline 7 & B1.7 and $M 2.7$ & OCLI multi-layer oxide UV blocker/2 mil white Tedlar ${ }^{(18}$ \\
\hline 8 & B 1.8 and M2.8 & 5 mil FEP/Al (current HST material) \\
\hline 9 & $\mathrm{~B} 1.9$ and $\mathrm{M} 2.9$ & $\mathrm{SiO}_{2} / \mathrm{Al}_{2} \mathrm{O}_{3} / \mathrm{Ag} / \mathrm{Al}_{2} \mathrm{O}_{3} / 4 \mathrm{mil}$ stainless steel \\
\hline 10 & $\mathrm{~B} 1.0$ and $\mathrm{M} 2.0$ & Proprietary Teflon ${ }^{2}$ FEP/AZ93 White Paint/Kapton \\
\hline
\end{tabular}

As previously mentioned, sets of samples were subsequently exposed to different environmental exposures (electron/proton radiation, atomic oxygen, simulated solar flare $x$-rays, thermal cycling and near ultraviolet radiation) at various facilities. The samples that were exposed to simulated solar flare x-rays at LeRC were B1.1-B1.8 and B1.0, and M2.1-M2.8. The samples that were exposed to thermal cycling at LeRC were samples B1.1-B1.8 (samples M2.1-2.8 were thermal cycled at GSFC). Prior to environmental exposure, all samples were purposely cut through approximately one quarter of its width, $5.08 \mathrm{~cm}$ (2") from the top. ${ }^{9}$ This was done to provid: a stress concentration area during environmental testing. Samples in the "B" set were exposed to charged particle radiation at The Boeing Company's Radiation Effects Laboratory (Boeing). These samples were 3.81 $\mathrm{cm}(1.5$ ") wide and $12.7 \mathrm{~cm}$ (5") long. Samples in the "M" set were exposed to charged particle radiation at the NASA Marshall Space Flight Center (MSFC) Space Environmental Effects (SEE) facility. These $3.81 \mathrm{~cm}$ (2") wide samples were cut to $6.7 \mathrm{~cm} \mathrm{(2.6")} \mathrm{in}$ length to fit in MSFC's facility.

\subsection{OPTICAL PROPERTY CHARACTERIZATION}

Optical properties were obtained using a Perkin-Elmer $\lambda-9$ spectrophotometer equipped with a $150 \mathrm{~mm}$ integrating sphere. Total spectral reflectance and total spectral transmittance were obtained from 250 to $2,500 \mathrm{~nm}$. The spectral data were convoluted into the air mass zero solar spectrum over the same wavelength range and integrated to obtain solar total reflectance $\left(\rho_{t}\right)$ and solar total transmittance $\left(\tau_{t}\right)$. Solar absorptance $\left(\alpha_{s}\right)$ was calculated by subtracting $\rho_{t}$ from 1 for the opaque samples, $;$ nd by subtracting $\rho_{t}+\tau_{t}$ from 1 for the transmitting samples. Instrument repeatability is \pm ).005. The thermal emittance $(\varepsilon)$ of Al-FEP retrieved during SMI did not change with envi onmental exposure, ${ }^{2}$ and therefore was not measured in this test program. Typically, the $\varepsilon$ for 5 mil Al-FEP is $0.81 .^{10}$ 


\subsection{SURFACE AND MASS CHARACTERIZATION}

Mass measurements were obtained using a Sartorius balance. Three readings were obtained and averaged for each measurement. The balance has an uncertainty of $\pm 50 \mu \mathrm{g}$. Overall photographs of the samples were obtained using a Polaroid Land camera. Optical micrographs and sample examinations were conducted using an Olympus SZH stereo microscope. Micrographs were obtained at magnifications between 12 and 101 times. A JEOL 6100 scanning electron microscope (SEM) was used for high magnification imaging. Samples were coated with a thin $(\approx 75 \AA)$ palladium conductive coating prior to SEM examination.

\subsection{CHARGED PARTICLE RADIATION}

Samples were exposed to charged particle radiation at either MSFC or at Boeing prior to environmental exposure at LeRC. At MSFC, the M samples were exposed to 10 years equivalent HST dose (SM3-2010) of electron and proton radiation. ${ }^{11}$ Samples were exposed to $50 \mathrm{keV}, 220 \mathrm{keV}$ (for 10 mil FEP) or $500 \mathrm{keV}$ (for 5 mil FEP) electrons and $700 \mathrm{keV}$ protons simulating the dose versus depth profile which was calculated for HST. The samples ( 2 inch wide) were loaded under a $10 \mathrm{lb}$. tensile load during exposure. Samples were desired to be stressed during environmental exposures. A $10 \mathrm{lb}$. load was applied to the samples because that is the load (for a 2 inch wide sample) which approximates the stress calculated to be necessary to hold 5 mil FEP flat (on HST) when it would otherwise curl-up tight like the retrieved SM2 sample when unconstrained. At Boeing, the B samples were exposed to a 10 year fluence of electron and proton radiation. ${ }^{12}$ Rather than simulating dose versus depth, Boeing simulated the total fluence using $40 \mathrm{keV}$ electrons $\left(3.1 \times 10^{1.3} \mathrm{e} / \mathrm{cm}^{2}\right)$ and $40 \mathrm{keV}$ protons $\left(2.7 \times 10^{10} \mathrm{p} / \mathrm{cm}^{2}\right)$. Ultraviolet radiation from a xenon arc source (i.e. a continuum from $200-400 \mathrm{~nm}$ ) illuminated the samples at approximately $1.2 \mathrm{UV}$ suns intensity during radiation exposure, resulting in approximately $5 \mathrm{UV}$ solar hours exposure. These samples ( $1.5 \mathrm{inch}$ wide) were also loaded under a $10 \mathrm{lb}$. tensile load during irradiation.

\subsection{SIMULATED SOLAR FLARE X-RAY EXPOSURE}

The x-ray fluences predicted for HST from SM3 to the year 2010 are $397.4 \mathrm{~J} / \mathrm{m}^{2}$ for $1-8 \AA \mathrm{x}$-rays, $28.05 \mathrm{~J} / \mathrm{m}^{2}$ for $0.5-4 \AA \mathrm{x}$-rays and $0.00967 \mathrm{~J} / \mathrm{m}^{2}$ for $0.124-0.5 \AA \mathrm{x}$-rays. These fluence values were calculated at GSFC based on GOES data, which were extrapolated, based on the 11 year solar cycle. The fluence is substantially higher for the 1-8 $x$-rays $(12,396-1,550 \mathrm{eV})$ than for the more energetic $x$-rays. These lower energy solar flare $x$-rays are often referred to as soft $x$-rays. Although FEP is transparent at visible wavelengths, it is highly absorbing between the vacuum ultraviolet to soft $x$-ray range of 25 to $3000 \mathrm{eV}^{8}$ If one looks at the $\mathrm{x}$-ray attenuation length versus photon energy for FEP, as seen in Figure 2, it becomes apparent that energy below $3000 \mathrm{eV}$ is primarily absorbed in the top $20 \mu \mathrm{m}$ of the film. Energy between $3000 \mathrm{eV}$ and $6000 \mathrm{eV}$ is primarily absorbed in the bulk of a FEP film $127 \mu \mathrm{m}$ thick. The transmittance versus energy curve for $127 \mu \mathrm{m}$ thick FEP shows that 84 percent of photons with energy of $10,000 \mathrm{eV}$ pass through the 


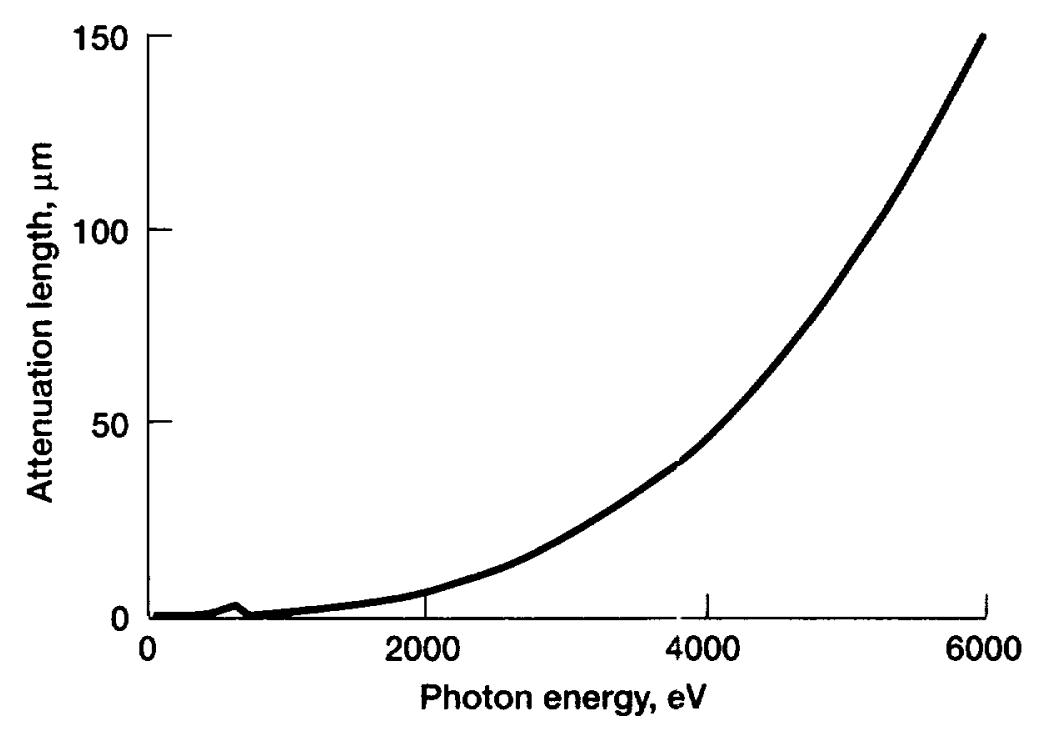

Figure 2. X-ray attenuation length versus photon energy $(0-6000 \mathrm{eV})$ for FEP.

film. $^{8}$ It was therefore concluded that irradiation with continuous $\mathrm{x}$-rays below $10 \mathrm{keV}$ would provide the $\mathrm{x}$-ray energies that should be necessary for bulk film degradation as seen on HST.

The samples were exposed to simulated solar flare $\mathrm{x}$-rays in a modified electron beam evaporator system. A water-cooled molybdenum (Mo) target was irradiated with a $10 \mathrm{keV}$ electron beam. The target was angled to allow the highest flux of $x$-rays to irradiate the candidate materials. The electron beam current was run low enough to prevent any evaporation of the target material. A model AXUV-20HEI absolute XUV silicone photodiode, produced by International Radiation Detectors Inc., was used to measure the $\mathrm{x}$-ray flux during each sample exposure run. The photodiode has 100 percent quantum efficiency over the range of photon energies produced by the source. Two sheets of $2 \mu \mathrm{m} \mathrm{Al} \mathrm{foil} \mathrm{were}$ used as a barrier between the target and the photodiode and samples during the exposures. The $\mathrm{Al}$ foil blocked energetic electrons from the target, and blocked the detector from visible light from the electron beam emitter. A photographic cloth was used to block room light to the detector.

To maximize the $\mathrm{x}$-ray flux, only one candidate sample was exposed at a time. With each candidate sample, a witness Al-FEP ( 5 mil FEP) iensile sample was exposed to evaluate the effect of $\mathrm{x}$-ray radiation on the tensile properties of Al-FEP. Figure 3 is a drawing of the electron beam system configured to expose the HST candidate samples to $x$-rays. Figure 4 shows the $x$-ray spectrum as a function of energy for a $10 \mathrm{keV}$ electron beam bombarding a Mo target, and with the $x$-rays passing through a $4 \mu \mathrm{m}$ Al barrier. This spectrum was obtained using a windowless energy-dispersive spectrometry (EDS) detector on a scanning electron microscope. With an electron beam energy of $10 \mathrm{keV}$, a Mo target will not produce any $\mathrm{K}$-alpha characteristic radiation $(17,476 \mathrm{eV})$, eliminating the very intense K-alpha characteristic p:ak. Yet, as can be seen in Figure 4, there is still a fairly substantial Mo L-alpha line at 2,193 eV (which appears wider in this 


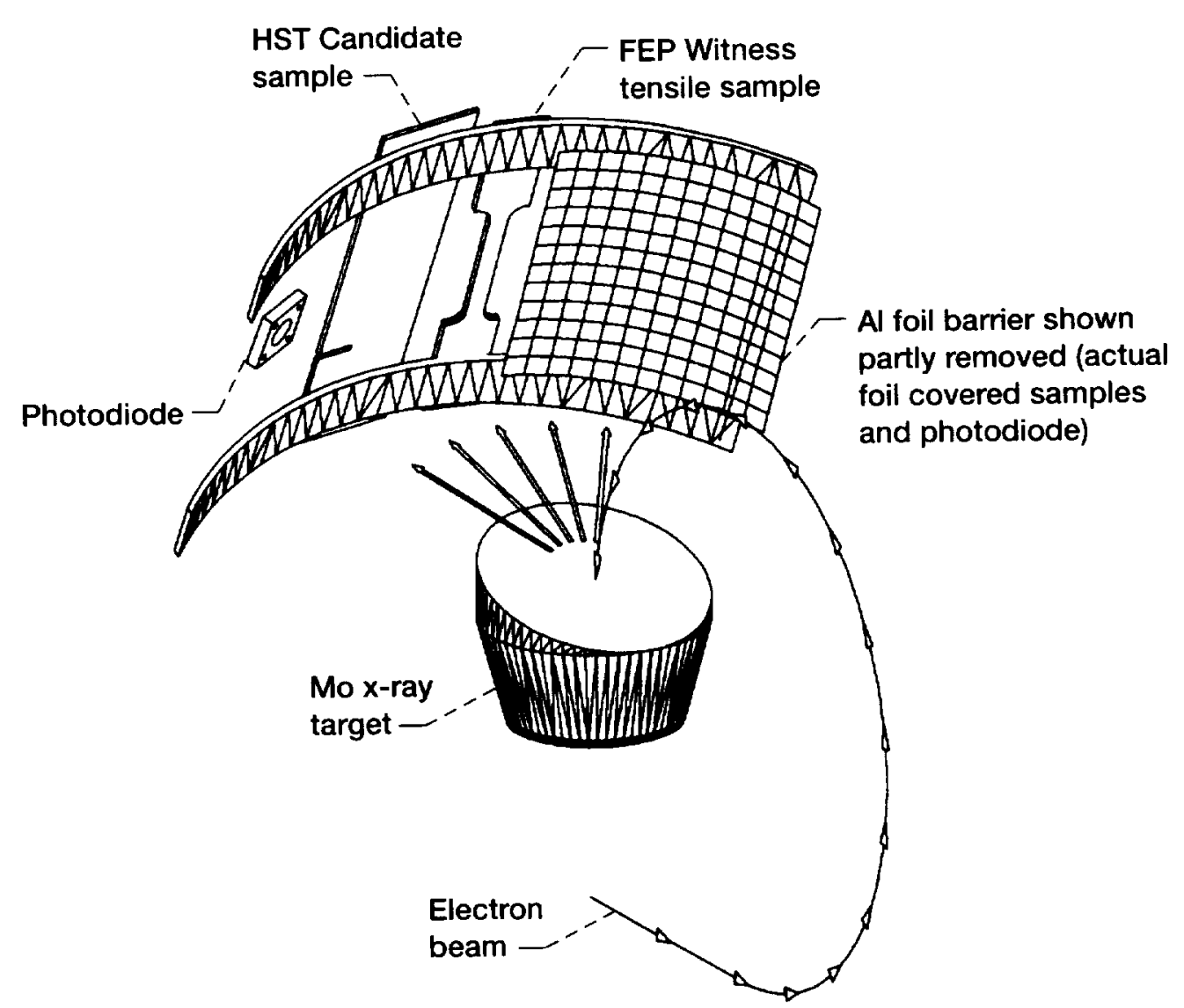

Figure 3. Drawing of the electron beam system configured to expose the HST candidate samples to Mo x-rays.

spectra than the actual peak width, which is a detector artifact). As can be seen in Figure 4, there is Bremsstrahlung, or continuous radiation between the energy range of 3000 to $6000 \mathrm{eV}$, and above, where bulk damage is anticipated to occur in FEP. The actual fluence exposures for each candidate sample are listed in Table 2. Due to electron beam gun controller fluctuations, the final fluence values varied somewhat from the desired $397.4 \mathrm{~J} / \mathrm{m}^{2}(457 \pm 50 \AA)$. After simulated solar flare $\mathrm{x}$-ray exposure characterization, the $M$ samples were returned to GSFC for thermal cycling.

\subsection{THERMAL CYCLING}

Samples B1.1-B 1.8 were thermal cycled in LeRC's Rapid Thermal Cycling Facility. The facility consists of two smaller chambers, hot over cold held at fixed temperatures, and frames that shuttle the samples between the two chambers. The hot side is heated via resistive heater elements and a low flow circulating fan to minimize the gradient. The cold side is cooled using liquid nitrogen which is fed into the chamber through a vented pipe; 


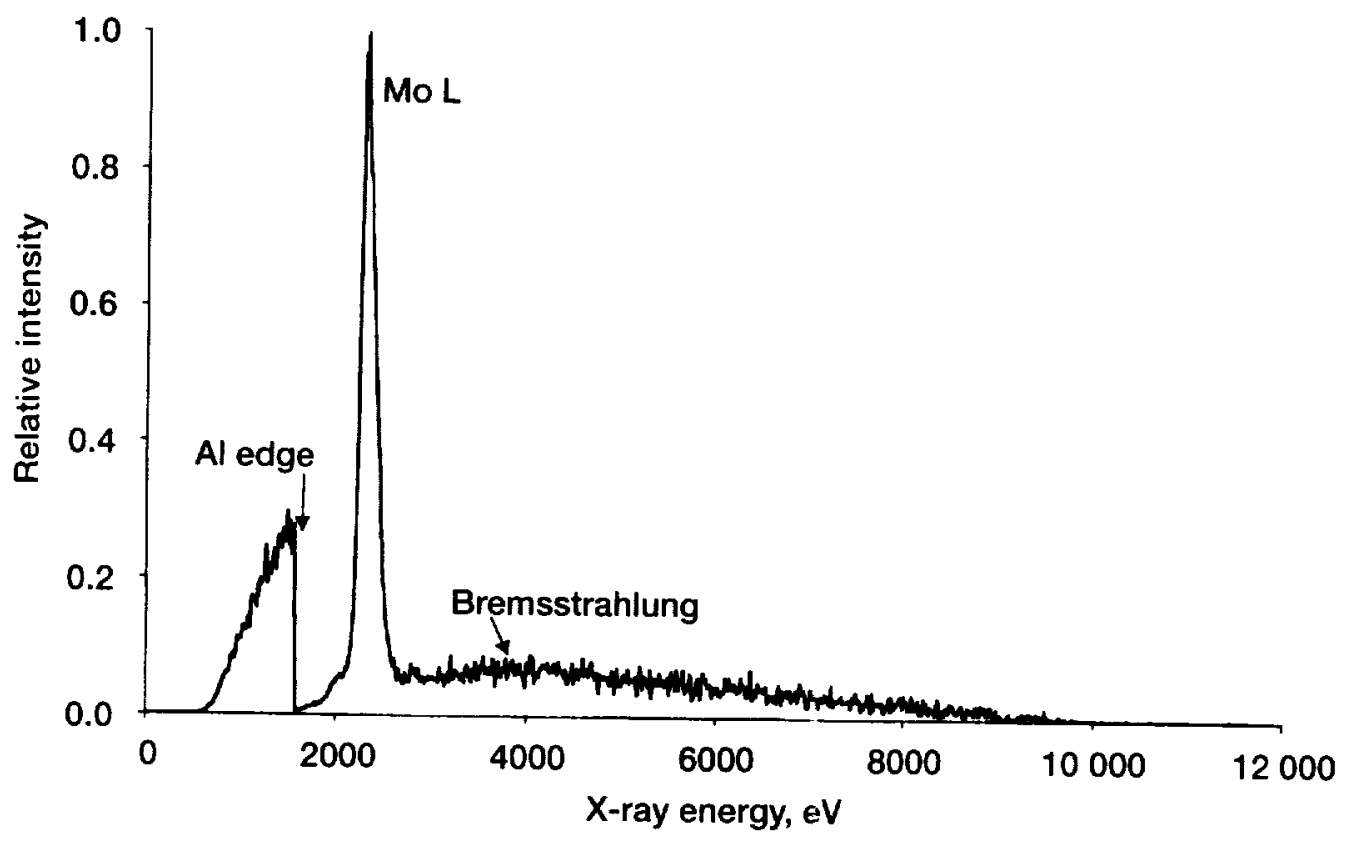

Figure 4. X-ray spectrum as a function of energy for a $10 \mathrm{keV}$ electron beam impacting a Mo target, and with the $\mathrm{x}$-rays passing through a $4 \mu \mathrm{m}$ Al barrier.

the nitrogen sprays away from the samples. Gaseous nitrogen fills the chambers and provides an inert atmosphere. Additionally, there is a nitrogen line to provide cooling on the hot side and a heater on the cold side to improve the temperature stability, and to provide some temperature profiling if needed. Typically, samples are mounted to frames attached to lever arms. The lever arms are air driven which raises and lowers the samples between the two chambers. A flange on the end of the frame: seals the frame in each chamber preventing thermal leakage between the two chambers. The facility is computer controlled; all valves and relays are operated based on temperatur: sensors in the chambers and on or near the samples. This control allows the samples to cycle as rapidly as possible.

The candidate samples were cycled from $-100^{\circ} \mathrm{C}$ to $+50^{\circ} \mathrm{C}$. The thermal mass of the samples was extremely low and therefore a thermocouple was not attached to the samples but only placed freely next to them. The candidate samples were each tensioned in metal fixtures under $10 \mathrm{lb}$. loads, (1,778 psi for sample B 1.8) and four of these fixtures were then mounted to each of the two chamber frames. The weight of these chamber frames was above the capability of the air cylinders and counterwe ights were added to the lever arms to obtain transition between the two temperature chambers. The chambers are set up vertically and therefore must work with or against gravity. Tlie additional dynamic forces caused by the motion of the frames during transition may have added some non-thermal stresses to the coupons during cycling. These samples were cycled for 1000 cycles. 
Table 2. X-Ray Fluences and Tensile Properties for Witness Al-FEP

\begin{tabular}{|l|c|c|c|}
\hline Sample & $\begin{array}{c}\text { X-Ray Fluence } \\
\left(\mathbf{J} / \mathbf{m}^{2}\right)\end{array}$ & $\begin{array}{r}\text { Tensile Properties of Companion } \\
\text { 5 mil Al-FEP Witness Samples }\end{array}$ \\
\hline & & UTS (MPa) & \% Elongation \\
\hline B1.1 & 431 & 15.4 & 163 \\
\hline B1.2 & 466 & 15.2 & 154 \\
\hline B1.3 & 447 & 19.1 & 226 \\
\hline B1.4 & 541 & 14.9 & 151 \\
\hline B1.5 & 521 & 16.3 & 178 \\
\hline B1.6 & 439 & 17.3 & 201 \\
\hline B1.7 & 488 & 15.1 & 160 \\
\hline B1.8 & 540 & 14.8 & 150 \\
\hline B1.0 & 401 & 16.9 & 183 \\
\hline M2.1 & 411 & 16.6 & 190 \\
\hline M2.2 & 399 & 14.8 & 150 \\
\hline M2.3 & 429 & 18.3 & 217 \\
\hline M2.4 & 414 & 16.0 & 177 \\
\hline M2.5 & 463 & 14.8 & 154 \\
\hline M2.6 & 399 & 17.4 & 202 \\
\hline M2.8 & 515 & 15.4 & 161 \\
\hline Average & $457 \pm 50$ & $16.1 \pm 1.3$ & $197 \pm 20$ \\
\hline 5 mil FEP/Al & 0 & $19.2 \pm 1.8$ & \\
\hline
\end{tabular}

\section{Results and Discussion}

\subsection{CHARGED PARTICLE RADIATION}

Optical micrographs, overall photographs, mass measurements and optical properties of the candidate materials after electron/proton radiation exposure by either Boeing (B samples) or MSFC (M samples) were obtained at LeRC prior to simulated solar flare $\mathrm{x}$-ray exposure. Details of the effect of electron/proton radiation exposure on candidate materials are reported in references 11 and 12. In summary, the MSFC samples experienced small changes in solar absorptance $(-0.001$ to +0.004$)$ and generally slight mass losses, attributed to vacuum dehydration. ${ }^{12}$ The Boeing samples experienced small changes in solar absorptance $(-0.003$ to +0.006$)$ with radiation exposure. ${ }^{11}$ The error of these solar absorptance measurements is 0.02 , indicating that no change in solar absorptance was measured after electron/proton exposure. Mass measurements were not reported. 


\subsection{SIMULATED SOLAR FLARE X-RAY EXPOS URE (SAMPLES M AND B)}

There were generally very small decreases in mass with $\mathrm{x}$-ray exposure $(-0.003$ to $-0.426 \%)$. The mass measurements are provided in Table 3 . The optical properties remained essentially unchanged with $\mathrm{x}$-ray exposure (a pristine NIST second surface mirror was optically characterized as a control). The optical properties are listed in Table 4. Optical microscopy showed no propagation, or change in the purposely induced cut mark, or in the general appearance of the samples with $\mathrm{x}$-ray exposure.

There were small decreases in the tensile properties of the companion Al-FEP witness samples exposed to $x$-ray radiation. The ultimate tensile strength (UTS) decreased from $19.2 \pm 1.8$ to $16.1 \pm 1.3 \mathrm{MPa}(2792 \pm 263$ to $2349 \pm 194 \mathrm{psi})$, and the percent elongation to failure decreased from $197 \pm 20$ to $176 \pm 25$ percent for pristine and $x$-ray exposed samples, respectively. The tensile properties of the witness samples are listed in Table 2 . The average $\mathrm{x}$-ray fluence was $457 \pm 50 \mathrm{~J} / \mathrm{m}^{2}$. It has been suggested that solar flare $\mathrm{x}$-rays are primarily responsible for the degradation of FEP on HST. ${ }^{13}$ The $x$-ray fluence ( $1-8 \AA$ ) for HST at the time of SMI has been calculated by GSFC to be $131.8 \mathrm{~J} / \mathrm{m}^{2}$ for the magnetometer surfaces which received 11.339 ESH exposure. Yet, the UTS for this sample was 13.6 MPa (1974 psi) and the percent elongation to failure was only 41.0 percent. ${ }^{8}$ These results, along with additional $x$-ray exposure tests reported by Banks, et. al., ${ }^{8}$ and vacuum ultraviolet radiation and sofi $x$-ray expowure tests reported by Dever, ${ }^{7}$ indicate that solar flare $x$-rays alone can not be the priman contributor to degradation of FEP on HST. This is consistent with the fact that MLI degradation cecurred on all sides of HST, not only solar facing sides.

Table 3. HST Candidate Samples Mass Measurements

\begin{tabular}{|c|c|c|c|c|c|c|}
\hline Sumple & $\begin{array}{c}\text { Ponc e } / p^{+} \text {Mass } \\
\text { (g) }\end{array}$ & $\begin{array}{c}\text { Post } \\
\text { X-Ray Mass }\end{array}$ & $\begin{array}{c}\% \\
\text { Change }\end{array}$ & Post T.C. Mass & $\begin{array}{c}\text { \% Change } \\
\text { from Post } \\
\text { X-ray } \\
\end{array}$ & $\begin{array}{c}\text { \% Change } \\
\text { from Post } \\
\mathrm{e}^{-} / \mathrm{p}^{+}\end{array}$ \\
\hline III.1 & $2.576 .2 \pm 01.060) 10$ & $2.756 .39 \pm 0.00001$ & -0.045 & $2.75607 \pm 0.00022$ & -0.012 & -0.057 \\
\hline B।.2 & $1.15(5(x) \pm 0 .(50) 16$ & $1.95516 \pm 0.00004$ & -0.042 & $1.95445 \pm 0.00004$ & -0.079 & -0.079 \\
\hline BI.? & $2.73 \times+2 \pm 0.000039$ & $2.73756 \pm 0.00010$ & -0.031 & $2.73648 \pm 0.00010$ & -0.039 & -0.071 \\
\hline BI.t & $1130.44 \pm 0.0001919$ & $1.93884 \pm 0.00008$ & -0.031 & $1.93713 \pm 0.00003$ & -0.088 & -0.119 \\
\hline $\mathrm{B} 1.5$ & $1+3776 \pm 0.000(09$ & $1.43781 \pm 0.00002$ & +0.003 & $1.43727 \pm 0.00003$ & -0.038 & -0.034 \\
\hline BI.6 & $1+3027 \pm 0 .(1)(0) 1.5$ & $1.42919 \pm 0.00003$ & -0.076 & $1.42852 \pm 0.00004$ & -0.047 & -0.122 \\
\hline B1.7 & $0 .+8(x)+0.00006$ & $0.48087 \pm 0.00002$ & -0.019 & $0.48066 \pm 0.0001$ & -0.044 & -0.062 \\
\hline B1.s & $1.20512 \pm 0.00005$ & $1.29487 \pm 0.00008$ & -0.019 & $1.2^{4} 569 \pm 0.00004$ & +0.063 & +0.044 \\
\hline B1.0 & $1 .+5.3860 \pm 0.00005$ & $1.44767 \pm 0.00017$ & -0.426 & - & - & - \\
\hline M2.1 & $1.96282 \pm 0.00002$ & $1.96165 \pm 0.00003$ & -0.060 & - & - & - \\
\hline $\mathrm{M} 2.2$ & $1.34966 \pm 0.00007$ & $1.34761 \pm 0.00002$ & -0.152 & - & - & - \\
\hline $\mathrm{M} 2.3$ & $1.96205 \pm 0.00001$ & $1.96047 \pm 0.00012$ & -0.081 & - & - & - \\
\hline M2.4 & $1.32761 \pm 0.00001$ & $1.32544 \pm 0.00006$ & -0.163 & - & - & - \\
\hline M2.5 & $0.96760 \pm 0.00010$ & $0.966 .34 \pm 0.00004$ & -0.130 & - & - & - \\
\hline M2.6 & $1.00858 \pm 0$ & $1.00706 \pm 0.00016$ & -0.151 & - & - & - \\
\hline $\mathrm{M} 2.8$ & $0.88820 \pm 0.00005$ & $0.88817 \pm 0.00003$ & -0.003 & . & - & - \\
\hline
\end{tabular}


Table 4. HST Candidate Samples Optical Properties

\begin{tabular}{|c|c|c|c|c|c|c|c|c|}
\hline \multirow[t]{2}{*}{ Sample } & \multicolumn{2}{|c|}{ Post $\mathrm{e}^{-} / \mathrm{p}^{+}$} & \multicolumn{2}{|c|}{ Post X-Ray } & \multirow{2}{*}{$\begin{array}{c}\begin{array}{c}\text { Absolute } \\
\text { Change }\end{array} \\
\alpha_{\mathrm{s}}\end{array}$} & \multicolumn{2}{|c|}{$\begin{array}{l}\text { Post Thermal } \\
\text { Cycling }\end{array}$} & \multirow{2}{*}{$\begin{array}{c}\text { Change from } \\
\text { Post X-ray } \\
\alpha_{s}\end{array}$} \\
\hline & $P_{1}$ & $\boldsymbol{\alpha}_{\mathrm{s}}$ & P & $\alpha_{s}$ & & $P_{t}$ & $\alpha_{s}$ & \\
\hline B 1.1 & 0.923 & 0.077 & 0.923 & 0.077 & 0 & 0.860 & 0.140 & +0.063 \\
\hline B 1.2 & 0.932 & 0.068 & 0.933 & 0.067 & -0.001 & 0.930 & 0.070 & +0.003 \\
\hline B 1.3 & 0.847 & 0.153 & 0.847 & 0.153 & 0 & 0.852 & 0.148 & -0.005 \\
\hline B 1.4 & 0.814 & 0.186 & 0.814 & 0.186 & 0 & 0.812 & 0.188 & +0.002 \\
\hline B1.5 & 0.927 & 0.073 & 0.924 & 0.076 & +0.003 & 0.883 & 0.117 & +0.041 \\
\hline B1.6 & 0.858 & 0.142 & 0.858 & 0.142 & 0 & 0.865 & 0.135 & -0.007 \\
\hline B 1.7 & 0.662 & 0.338 & 0.666 & $\begin{array}{c}0.334 \\
(* 0.252)\end{array}$ & -0.004 & 0.667 & $\begin{array}{c}0.333 \\
(* 0.251)\end{array}$ & -0.001 \\
\hline B 1.8 & 0.889 & 0.111 & 0.888 & 0.112 & +0.001 & 0.880 & 0.120 & +0.008 \\
\hline NIST 2023 & 0.883 & 0.117 & 0.883 & 0.117 & 0 & 0.883 & 0.117 & 0 \\
\hline B 1.0 & 0.844 & 0.156 & 0.847 & 0.153 & -0.003 & - & - & - \\
\hline M2.1 & 0.923 & 0.077 & 0.925 & 0.075 & -0.002 & - & - & - \\
\hline M2.2 & 0.933 & 0.067 & 0.936 & 0.064 & -0.003 & - & - & - \\
\hline M2.3 & 0.838 & 0.162 & 0.840 & 0.160 & -0.002 & - & - & - \\
\hline $\mathrm{M} 2.4$ & 0.824 & 0.176 & 0.827 & 0.173 & -0.003 & - & - & - \\
\hline $\mathrm{M} 2.5$ & 0.924 & 0.076 & 0.927 & 0.073 & -0.003 & - & - & - \\
\hline M2.6 & 0.859 & 0.141 & 0.861 & 0.139 & -0.002 & - & - & - \\
\hline $\mathrm{M} 2.8$ & 0.863 & 0.137 & 0.865 & 0.135 & -0.002 & - & - & - \\
\hline NIST 2023 & 0.883 & 0.117 & 0.886 & 0.114 & -0.003 & & & \\
\hline
\end{tabular}

* Sample has a transmittance of 0.064 , which was not measured post $\mathrm{e}^{1} / \mathrm{p}^{+}$exposure

NIST 2023: second surface Al mirror

\subsection{THERMAL CYCLING (SAMPLES B1.1-B1.8)}

Samples were originally loaded under $10 \mathrm{lbs}$. of tension. After 252 cycles for samples B 1.1 through B 1.4 , and 285 cycles for samples B 1.5 - B 1.8, thermal cycling automatically stopped and the chamber was opened up. Two samples had torn in half (B1.2 and B1.4, both with fiberglass scrim and Kapton ${ }^{\circledR}$ backed). Sample B1.8 (the current material, Al-FEP with no scrim) had torn about $90 \%$ through the width of the sample. The frames were then inverted to keep the samples from falling over during additional cycling, resulting in a $9 \mathrm{lb}$. tensile load for the remainder of cycling. Additional thermal cycling did not appear to cause further crack propagation. Figure 5 shows the candidate samples in the test facility after 1000 thermal cycles. The final tension was determined for the intact samples, and ranged between $5.05 \mathrm{lbs}$. (sample B1.8) to $8.19 \mathrm{lbs}$. (sample B1.7). Figures 6-8 show several samples as received at LeRC (after electron/proton exposure) and after thermal cycling (and $\mathrm{x}$-ray exposure). 


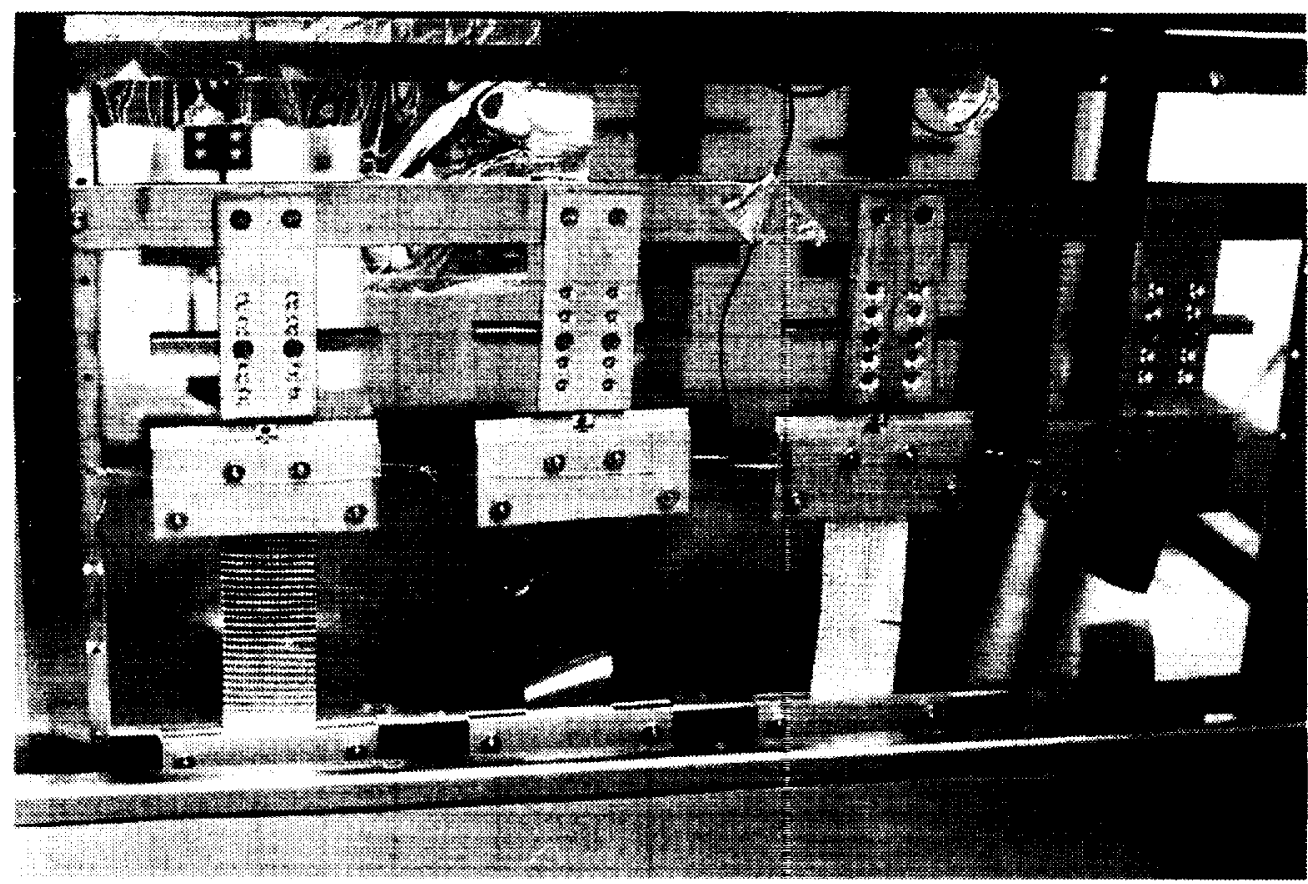

B1.1

B1.2

B1.3

B1.4

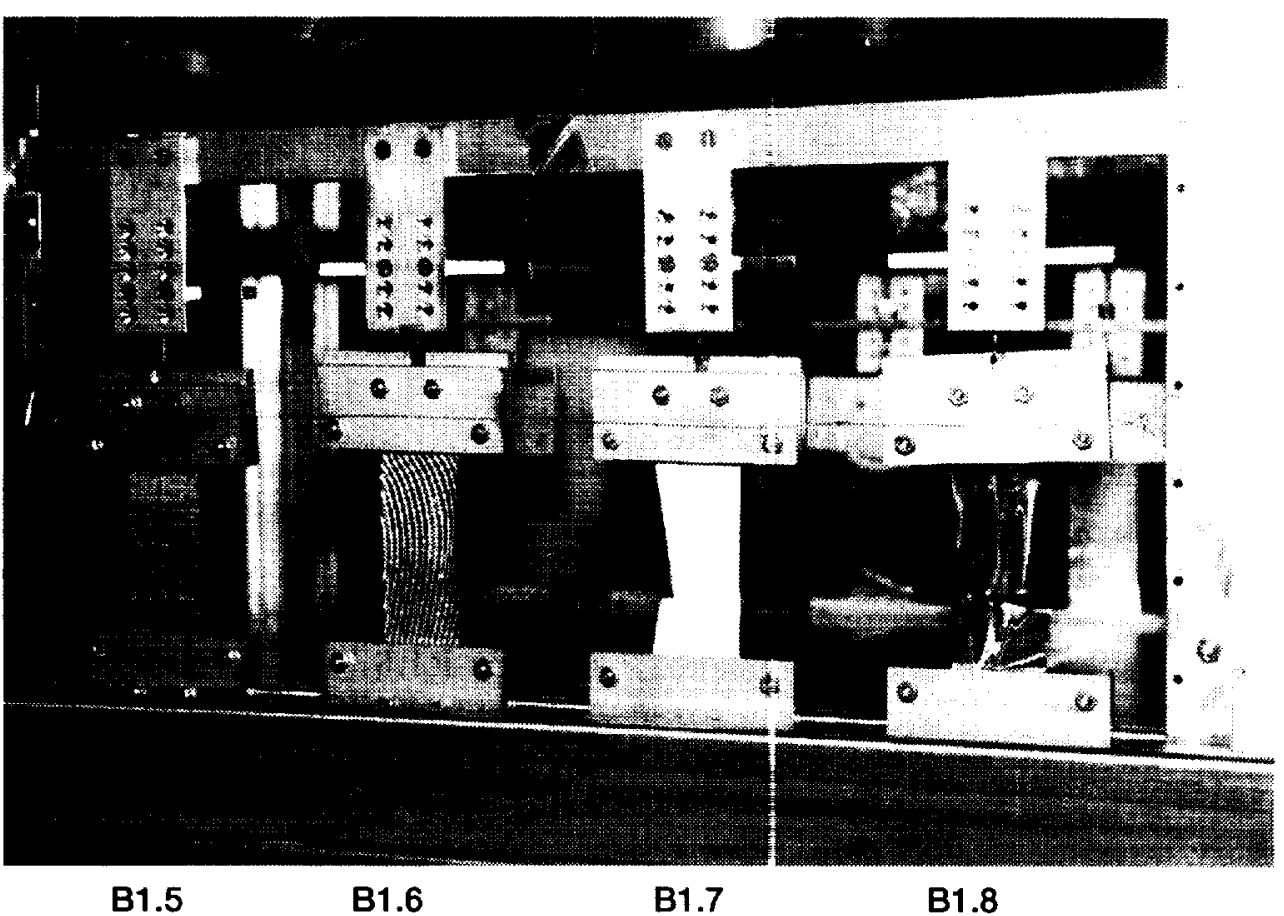

Figure 5. Candidate samples (B1.1 - B 1.8) under tension in the Rapid Thermal Cycling Facility after 1000 thermal cycles. 


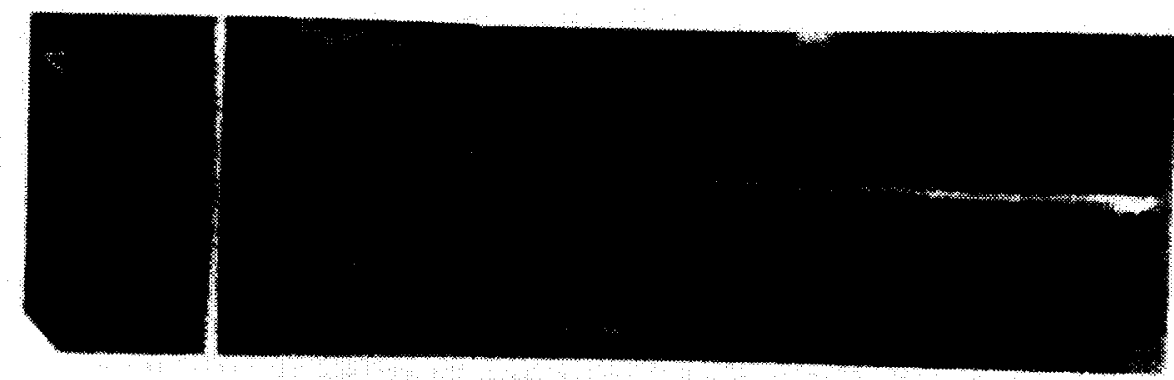
(a)

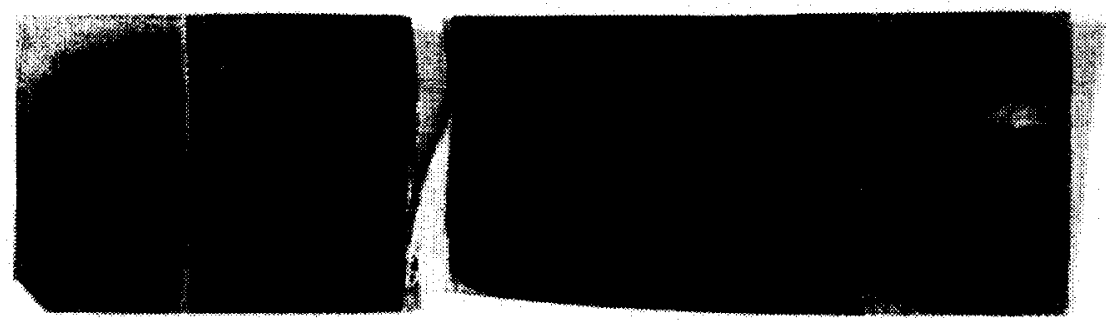

(b)

Figure 6. Candidate sample B 1.4 ( 5 mil FEP/Al/fiber glass scrim/adhesive/2 mil Kapton ${ }^{\circledR}$ ), (a) After $\mathrm{e}^{-/ \mathrm{p}^{+}}$radiation exposure. (b) After $\mathrm{e}^{-/ \mathrm{p}^{+}}$radiation exposure. $\mathrm{x}$-ray exposure and thermal covelino 


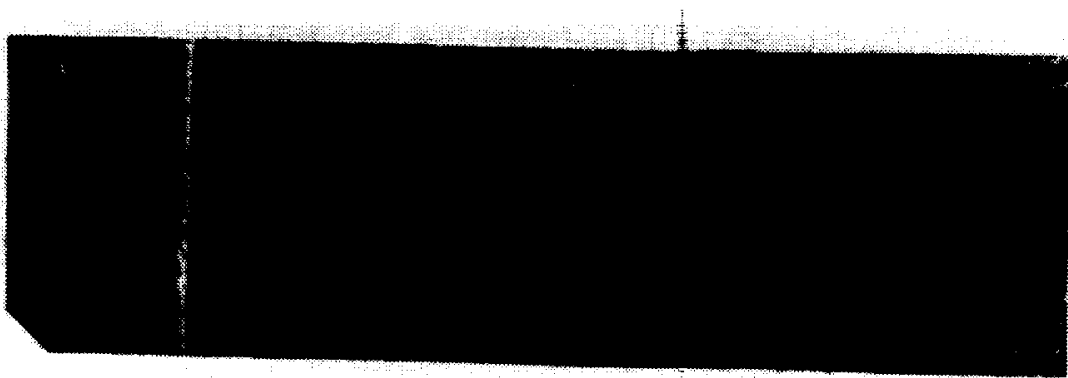

(a)

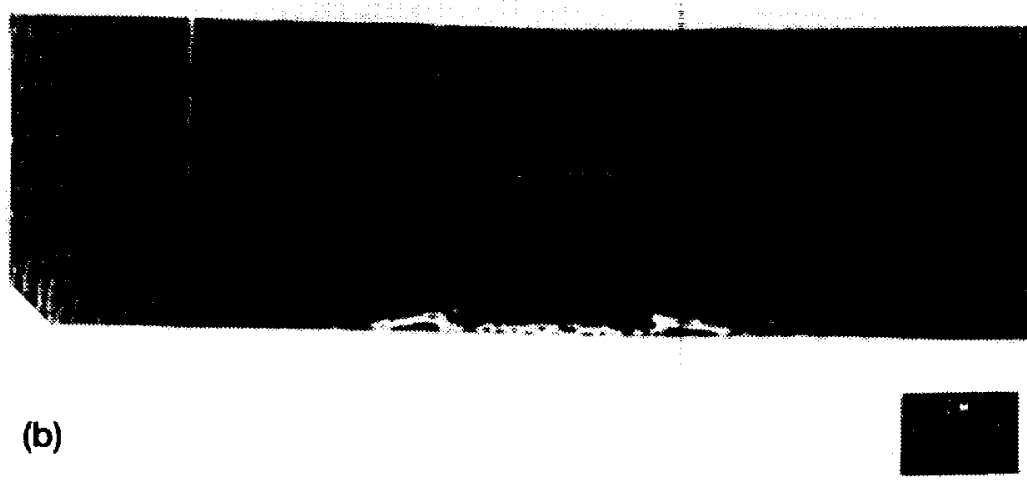

Figure 7. Candidate sample B 1.6 (5 mil FEP/Al/adhesive Nome $x^{\circledR}$ scrim). (a) After $\mathrm{e}^{-/ \mathrm{p}^{+}}$ radiation exposure. (b) After $\mathrm{e}^{-/ \mathrm{p}^{+}}$radiation exposure, $\mathrm{x}$-ray exposure and thermal cycling. 


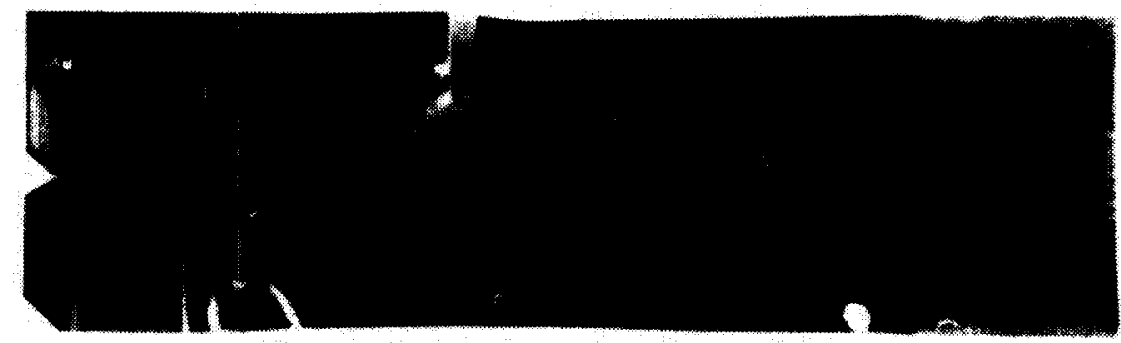

(a)

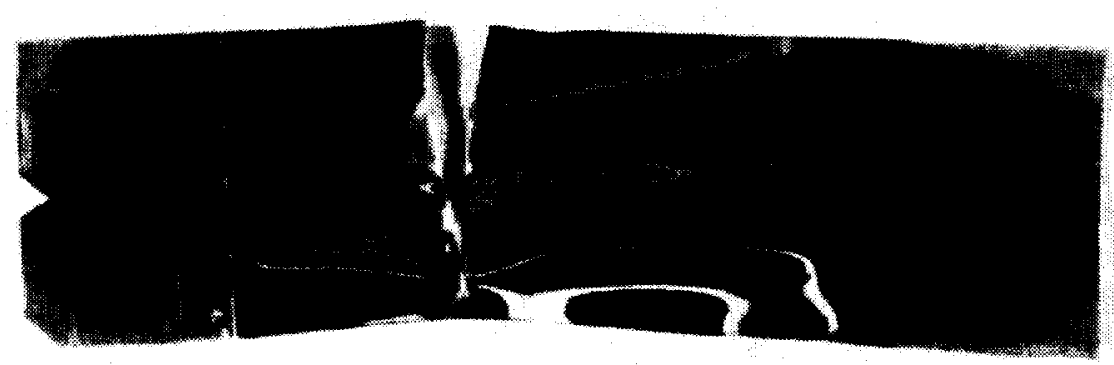

(b)

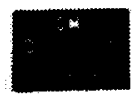

Figure 8. Candidate witness sample B1.8 (5 mil FEP/Al). (a) After $\mathrm{e}^{-/ \mathrm{p}^{+}}$radiation exposure. (b) After $\mathrm{e}^{-} / \mathrm{p}^{+}$radiation exposure, $\mathrm{x}$-ray exposure and thermal cycling. 
Generally, there were very small decreases in mass with thermal cycling $(<0.047 \%)$. These results are listed in Table 3 . The optical prorerties for the samples after thermal cycling are listed in Table 4 . Thermal cycling caused significant absorptance increases in sample B1.1 (+0.063) and sample B 1.5 (+0.041). These samples have areas which appear yellowed with thermal cycling. Both of these samples have Ag and the Nomex ${ }^{\circledR}$ (vs. fiberglass) scrim. Sample B1.8 had an absorptance increase of +0.008 with thermal cycling. Samples B1.3 and B1.6 had slight decreases in absorptance $(-0.005$ and -0.007 , respectively). Both these samples have Al and the Nomex ${ }^{\circledR}$ scrim. Samples B1.2 and B1.4 ( $\mathrm{Ag}$ and $\mathrm{Al}$, respectively) with fiberglass scrims had essentially no absorptance change.

Optical microscopy provided evidence that the yellowed area of samples BI.1 and B 1.5 are associated with the adhesive. Figure 9a shows that the yellowed area has a distinct pattern. Figure $9 \mathrm{~b}$ shows the same area, photographed with back-lighting. Figure $9 \mathrm{c}$ shows the backside of the sample. It can be seen in Figure $9 \mathrm{c}$ that the polyester adhesive in the rectangular regions in between the fibers has occasionally cured with adhesive-voids.
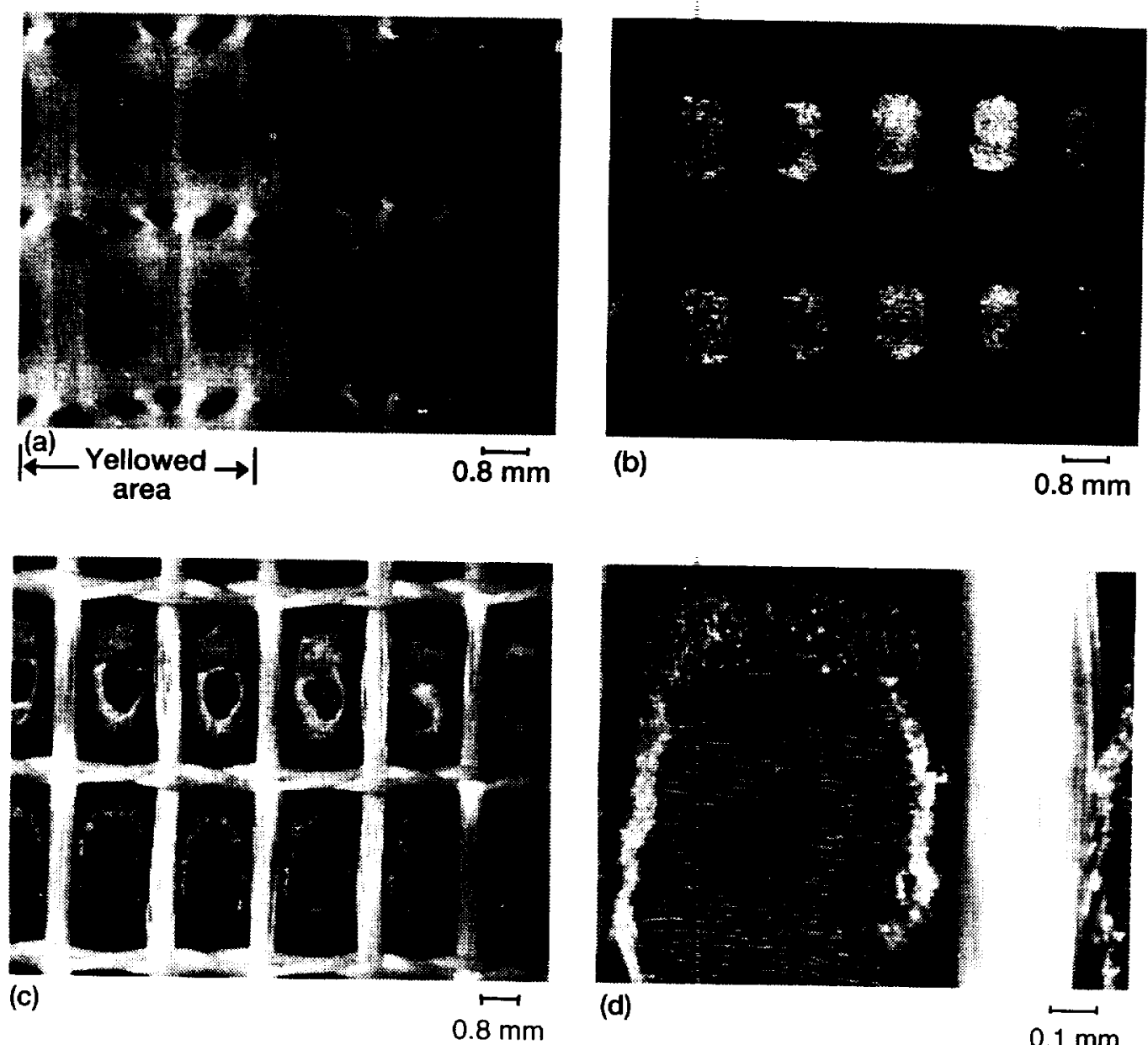

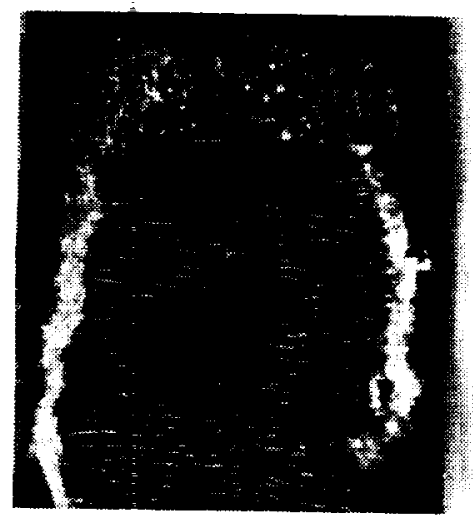

(d)

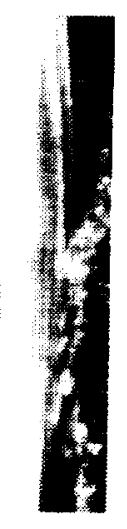

$0.1 \mathrm{~mm}$

Figure 9. Candidate sample B1.5 after thermal cycling showing dis soloration pattern. (a) Yellowed discolored area. (b) Same area as 9 (a) with back lighting. (c) Backsi le of sample showing adhesive void areas. (d) Close-up of an adhesive void (cracks are in metal layers). 
Table 5. Initial Cut Lengths and Tear Lengths after Thermal Cycling

\begin{tabular}{|c|c|c|c|}
\hline $\begin{array}{c}\text { Sample } \\
\text { Id. }\end{array}$ & $\begin{array}{c}\text { Initial Cut } \\
\text { Length } \\
\text { (mm) }\end{array}$ & $\begin{array}{c}\text { Tear } \\
\text { Length } \\
(\mathrm{mm})\end{array}$ & Candidate Material \\
\hline B 1.1 & $10.2\left(0.40^{\prime \prime}\right)$ & $1.8\left(0.07^{*}\right)$ & 10 mil FEP/Ag/Inconel/adhesive/Nomex scrim \\
\hline B 1.2 & $9.1\left(0.36^{\circ \prime}\right)$ & $28.7\left(1.13^{\prime \prime}\right)^{*}$ & $\begin{array}{l}5 \mathrm{mil} \text { FEP/Ag/Inconel/adhesive/fiberglass scrim/adhesive/2 mil } \\
\text { Kapton }^{(0}\end{array}$ \\
\hline $\mathrm{B} 1.3$ & $9.4\left(0.37^{\prime \prime}\right)$ & $5.3\left(0.2 I^{\prime \prime}\right)$ & 10 mil FEP/Al/adhesive/Nomex ${ }^{(3)}$ scrim \\
\hline B।.4 & $9.1\left(0.36^{\prime \prime}\right)$ & $28.7\left(1.13^{\prime \prime}\right)^{*}$ & 5 mil FEP/A 1/adhesive/fiberglass scrim/adhesive/2 mil Kapton \\
\hline $\mathrm{B} 1 . .5$ & $8.9(0.35 ")$ & $2.8\left(0.11^{\prime \prime}\right)$ & 5 mil FEP/Ag/Inconel/adhesive/Nomex ${ }^{3}$ scrim \\
\hline B 1.6 & $9.1\left(0.36^{\prime \prime}\right)$ & $5.1(0.20 ")$ & 5 mil FEP/A //adhesive/Nomex ${ }^{8}$ scrim \\
\hline $\mathrm{B} 1.7$ & $9.9\left(0.39^{\prime \prime}\right)$ & $5.3\left(0.21^{\prime \prime}\right)$ & OCLI multi-layer oxide UV blocker $/ 2$ mil white Tedlar $^{\sqrt[B]{B}}$ \\
\hline B 1.8 & $9.4\left(0.37^{\prime \prime}\right)$ & $24.6(0.97 ")$ & 5 mil FEP/Al (current HST material) \\
\hline
\end{tabular}

* Sample tore in half

A close-up of such a void in the adhesive is shown in Figure 9d. The fine lines are cracks in the metal layers due to thermal cycling. Looking at the yellow pattern in $9 \mathrm{a}$ and the pattern of transmitted light in $9 \mathrm{~b}$ associated with adhesive-voids, it becomes apparent that the discoloration is associated with the adhesive. It is not clear why the discoloration was not across the entire sample. As previously mentioned, both the discolored samples have $\mathrm{Ag}$ and Nomex ${ }^{\circledR}$ scrims and were supplied by Sheldahl with their non-UV darkening adhesive (FEP/Ag/Inconel/adhesive/Nomex ${ }^{\circledR}$ scrim). The Ag sample supplied by Sheldahl with a fiberglass scrim and Kapton ${ }^{\circledR}$ substrate (B1.2) did not discolor even though it had the same adhesive (FEP/Ag/Inconel/adhesive/fiberglass scrim/adhesive/Kapton ${ }^{\circledR}$ ). The Al samples provided by Dunmore with $\mathrm{Al}$ and Nomex ${ }^{\circledR}$ scrim (B1.3 and B1.6) did not yellow with thermal cycling (FEP/Al/adhesive/Nomex ${ }^{\circledR}$ scrim). It therefore appears that there is a discoloring problem with the Sheldahl adhesive and Nomex ${ }^{\circledR}$ scrim upon heating.

Optical microscopy was used to document the extent of damage which occurred at the purposely cut area with thermal cycling under load. The initial cut lengths and tear lengths propagated during thermal cycling are listed in Table 5. The fiberglass/Kapton ${ }^{\circledR}$ samples (B1.2 and B1.4) tore in half. The tear lengths for the Nomex ${ }^{\circledR}$ scrim samples ranged from $1.8 \mathrm{~mm}\left(0.071\right.$ ") to $5.3 \mathrm{~mm}\left(0.209\right.$ "). The Ag/Inconel Nomex ${ }^{\circledR}$ samples (B1.1 and B1.5) had shorter tears then the AI Nomex ${ }^{\circledR}$ samples (B1.3 and B1.6) of the same FEP thickness. The Nomex ${ }^{\circledR}$ scrim on the $\mathrm{Al}$ samples was not as orthogonal as the $\mathrm{Ag} / \mathrm{Inconel}$ samples (as can be seen by comparing B1.1 and B1.6 in Figure 5) which may have contributed to the small additional tearing. Sample B1.7 had a very fine hairline crack which was $5.3 \mathrm{~mm}$ long, and the witness Al-FEP sample (B1.8) had a tear length of $42.6 \mathrm{~mm}$. Figure 10 shows tearing of the cut tip in sample B1.6. The backside of the sample shown in Figure $10 \mathrm{~b}$ shows the tear extending to the second fiber bundle, with no damage to the uncut fiber bundles near the propagated tear.

Several tests were run to understand the exact mechanism responsible for the tear propagation of the thermal cycled samples. Because the tensile properties of FEP decrease with temperature, loaded samples were exposed to the high end temperature $\left(50^{\circ} \mathrm{C}\right)$ of the 

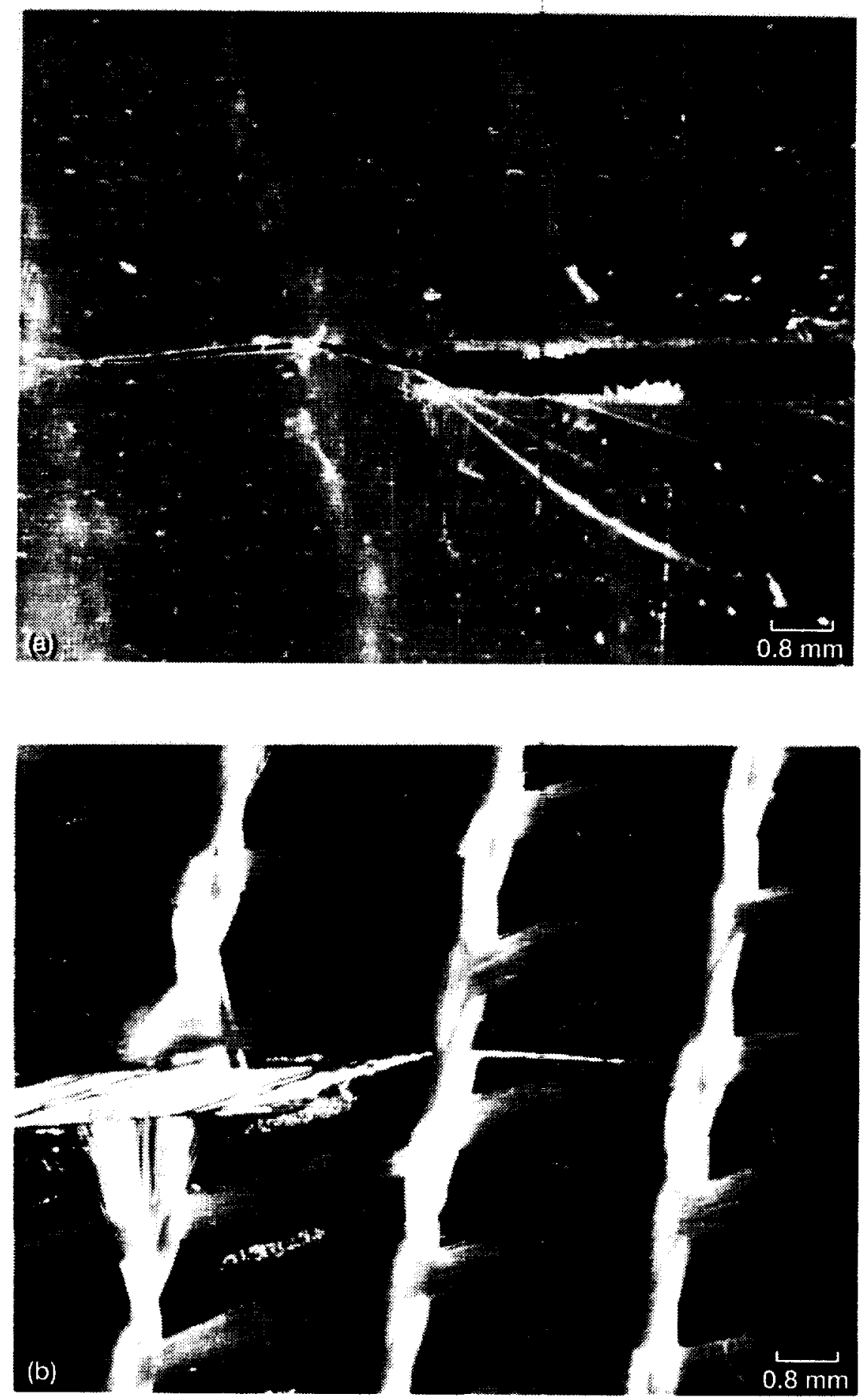

Figure 10. Candidate sample B1.6 after thermal cycling. (a) Close up of purposely cut region showing fine tear which propagated during the rmal cycling. (b) Backside of sample showing the tear extending to the seco id fiber bundle beyond the cut. 
thermal cycling range to see if tearing which occurred with thermal cycling was due to decreases in tensile strength with temperature. Four 5 mil Al-FEP samples with identical sample dimensions and purposely cut marks as the candidate samples were loaded under tension $\left(2.5,5.0,7.5\right.$ and $10 \mathrm{lb}$. loads) and exposed to $50^{\circ} \mathrm{C}$ for 90.5 hours (approximately the time the candidate samples were thermal cycled). There was no observed propagation of the cut with exposure under any of the applied loads. Al-FEP samples which were exposed to $50^{\circ} \mathrm{C}$ under load were then brought to liquid $\mathrm{N}_{2}$ temperature while under tension to see if the additional load due to contraction caused tear propagation. There was no observed propagation of the cut with exposure under any of the applied loads.

Four Al-FEP ( 5 mil) samples, which had not been previously exposed to electron/ proton or x-ray exposures, were thermal cycled under varying loads $(2.5,5.0,7.5$ and $10.0 \mathrm{lbs}$.). These samples also had identical geometry and cut marks as the candidate samples. After 250 cycles, the facility was stopped and opened up. No signs of tear propagation were observed at 250 cycles for any of the samples. After 1,000 cycles, small or no tears were observed for the $2.5,5.0$ and $7.5 \mathrm{lb}$. loaded samples, while the $10 \mathrm{lb}$. loaded sample was torn almost as far as candidate sample B1.8. Because of the thermal cycling test setup, additional loads are imposed on the samples as they move from the hot to the cold chamber, and vise-versa. Therefore, another set of 5 mil Al-FEP samples were prepared and mechanically cycled under load $(2.5,5.0,7.5$ and $10 \mathrm{lb}$. loads $)$ in the thermal cycling facility (at room temperature). After 250 mechanical cycles, the 2.5 and $5.0 \mathrm{lb}$. samples had no tear initiation, while the 7.5 and $10 \mathrm{lb}$. samples had very small tear initiations. After 1000 cycles, there was no tear propagation in either the 7.5 or the $10.0 \mathrm{lb}$. samples. These results indicate that the tearing which occurred in sample B1.8 was due to thermal cycling (versus thermal exposure) under the high load $(10 \mathrm{lb}$.). The prior radiation exposure does not appear to have contributed to tear propagation in samples $\mathrm{B} 1.8$ because radiation exposure was not necessary to cause tear propagation. Also, mechanical cycling under load was not sufficient without thermal cycling to cause tear propagation.

The cracks, which propagated on HST, were found to have very smooth surfaces. Figure 11 shows examples of these smooth, featureless crack morphologies. Figure $11 \mathrm{a}$ is an electron micrograph of an in-space-propagated crack from the LS MLI sample retrieved during SM2. Similar smooth crack surfaces were found on cracks located near cable holes in the magnetometer MLI retrieved during SM1, as shown in Figure $11 \mathrm{~b}$ and $11 \mathrm{c}$. These smooth cracks are believed to have occurred due to slow crack growth under low stress in the presence of a degrading environment. ${ }^{9}$ Similar findings were observed for the SADA MLI retrieved during SM1, and have been described as being similar to stress-cracking of glassy materials. ${ }^{4}$ When the embrittled SM2 MLI sample is purposely cracked by bending the FEP space exposed surface in tension, the crack surface is not smooth and glassy in appearance, but more fibrous as seen in Figure 12. This also supports the idea that the smooth cracks occurred slowly in the space environment. The Al-FEP sample which was thermal cycled under a $10 \mathrm{lb}$. load, with no prior radiation exposure, had a very different surface morphology. Its crack surface has wave-like striations, as seen in Figure 13. This surface is much more ductile than the glassy-looking surfaces which cracked in space. The crack morphology of this thermal cycled sample is identical to that of sample B1.8, which did receive prior radiation exposure. ${ }^{9}$ The additional radiation exposures (electron/proton and $x$-ray) did not affect the crack propagation morphology in this sample. The smooth 

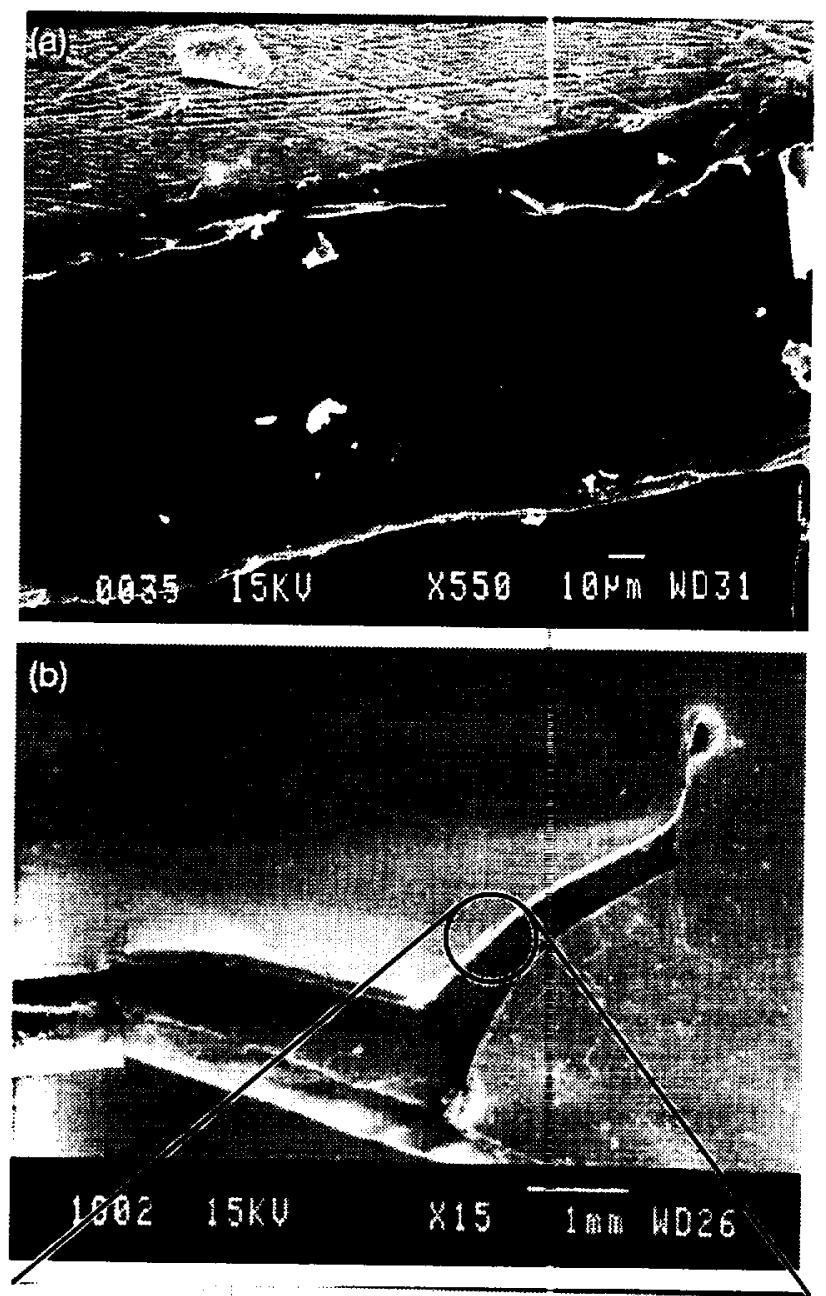

(c)

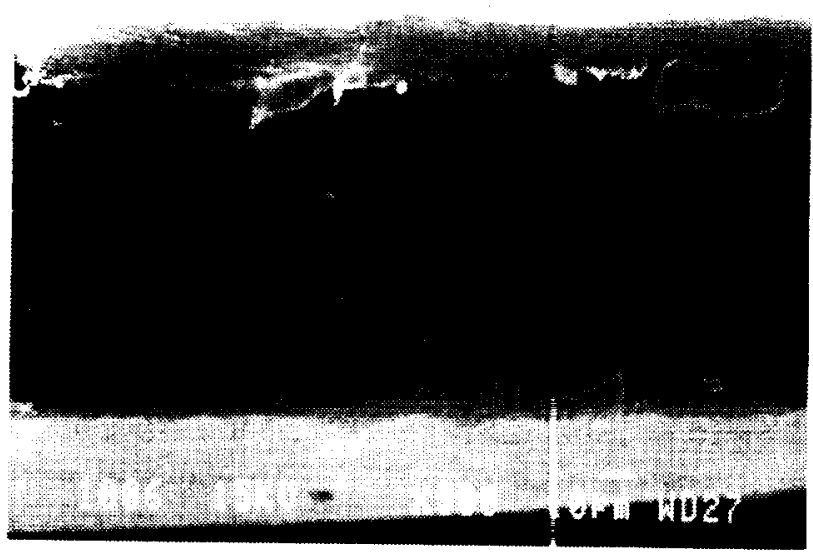

Figure 11. Smooth crack morphologies of in-s/ ace propagated cracks in HST FEP. (a) SM2 LS FEP. (b) SM1 MSS FEP near a cable hole. (c) Close-up of crack su face in 11(b). 


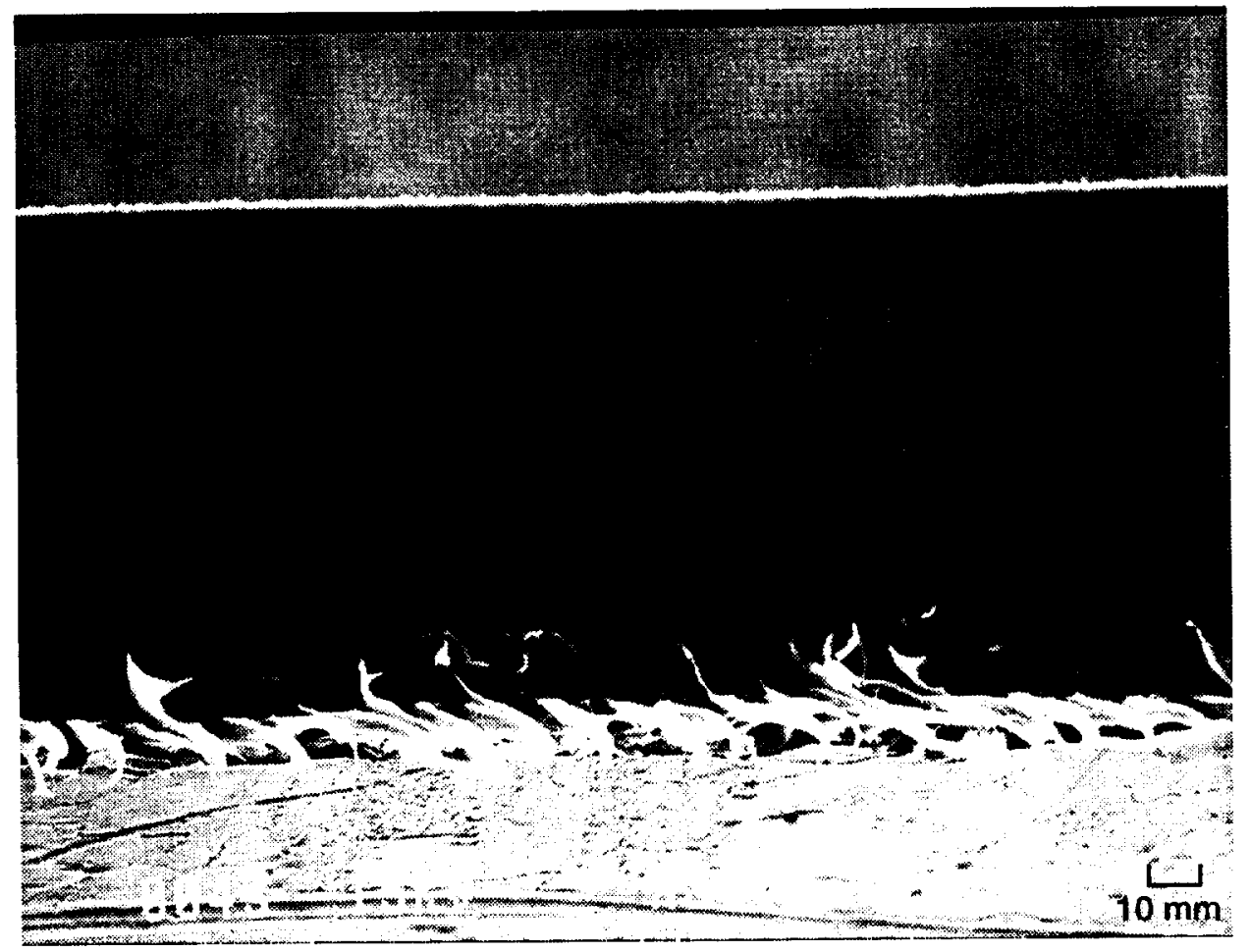

Figure 12. SM2 FEP after bending the space exposed FEP surface in tension. The tension induced fast-propagated crack has a fibrous. textured surface morphology. 


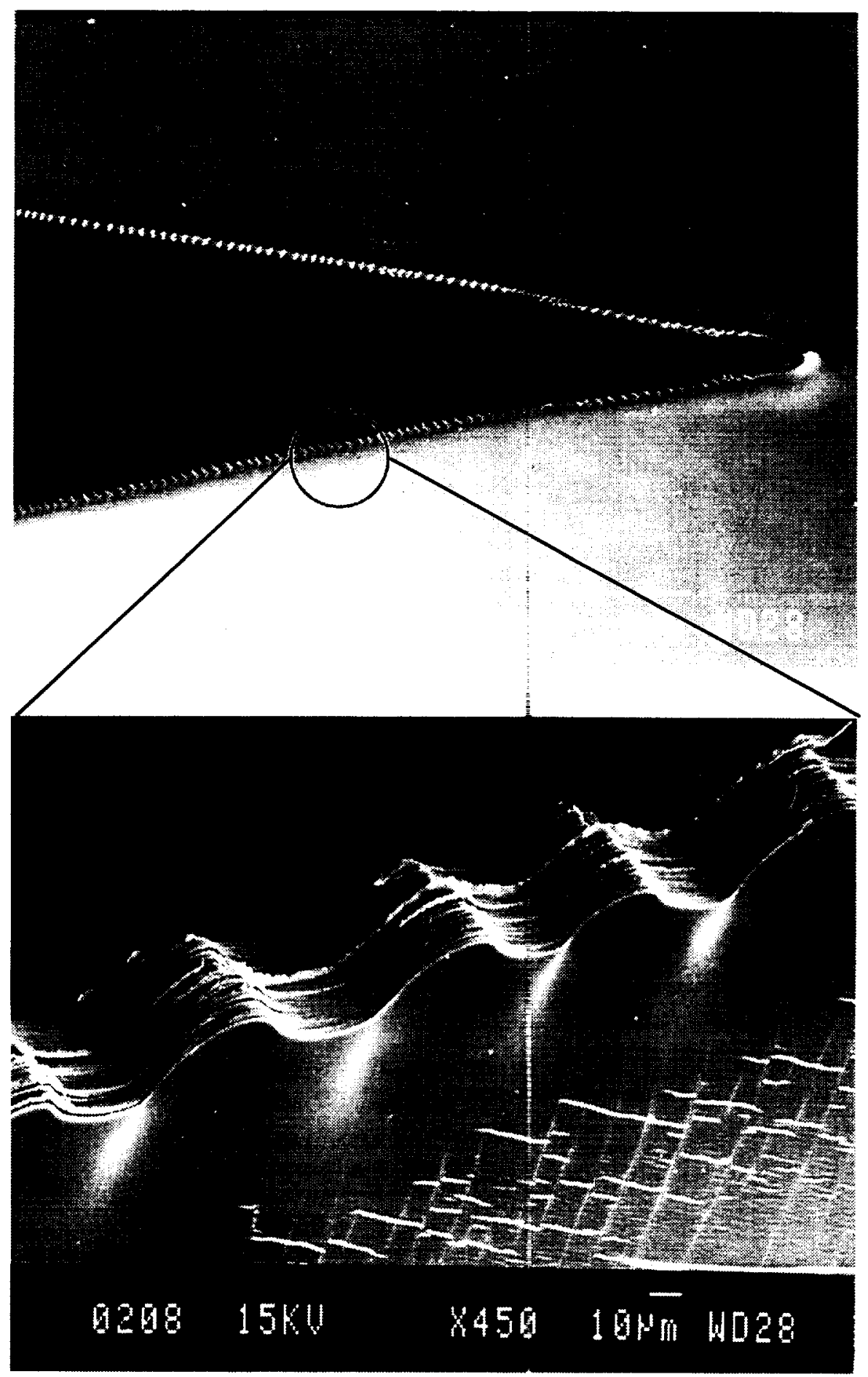

Figure 13. Surface morphology of FEP tear propagated tluring thermal cycling under load. This surface has ductile appearing, wave-like striations. 
crack morphology which occurred on HST was not observed for the B1 samples which were thermal cycled under tensile loading, although one sample with scrim backing (B1.5) had areas which were relatively smooth. ${ }^{9}$ However, relatively smooth crack morphology was observed with most of the GSFC tested samples containing scrim which were thermal cycled under constraint loading (taped at edges) and experienced crack propagation. ${ }^{9}$

Based on the environmental testing conducted at LeRC, candidate samples Bl.3 and B 1.6 (Al and Nomex ${ }^{\circledR}$ scrim, prepared by Dunmore) performed the best. Samples B 1.2 and B1.4 (with fiberglass scrim and Kapton ${ }^{\circledR}$ substrates) tore in half during thermal cycling under load. Samples B1.1 and B1.5 (with Ag and Nomex ${ }^{\circledR}$ scrim, prepared by Sheldahl) had significant increases in solar absorptance with thermal cycling which were attributed to an interaction of the adhesive and the Nomex ${ }^{\circledR}$ scrim with heating. Sample B 1.7 (an OCLI coated sample) has a high initial absorptance, and was tested because the HST project wanted to check its performance. Because the solar absorptance of B1.6 was lower than B1.3, the HST MLI candidate sample B1.6 was considered the single best performer (using solar absorptance as the determining factor between B1.3 and B1.6).

\section{Additional Testing}

After sample characterization at LeRC (mass, optical properties and optical microscopy) the candidate samples were returned to GSFC for further testing and/or analyses. The M2 sample set was thermal cycled under constraint loading at GSFC and then exposed to NUV radiation. Other candidate sample sets were exposed to environments including electron/proton radiation, atomic oxygen and thermal cycling (sample set M1), thermal cycling of large samples (samples set L1) and NUV radiation (sample set G1). ${ }^{9}$

\section{Final Ranking}

When testing of all candidate samples was completed, the HST MLI FRB met to review the results and revote on the candidate materials using the original multiplicative evaluation formula based on the original nine performance criteria. During the intervening months, the HST project decided to use the sample 9 material $\left(\mathrm{SiO} 2 / \mathrm{Al}_{2} \mathrm{O}_{3} / \mathrm{Ag} / \mathrm{Al}_{2} \mathrm{O}_{3} /\right.$ stainless steel) as the outer layer on all Bay repairs. The HST MLI FRB was then evaluating the test results for use on the HST LS and FS areas only. Based on this criteria, two of the original 10 materials (materials 9 and 10) were not considered in the final evaluation. Material 9 is not practical for the repairs because of handling (stainless steel sheets), and material 10 had problems with particulate contamination and UV darkening. ${ }^{9}$

The final ranking of the candidate materials is listed in Table 6. Material 6 (5 mil FEP/ $\mathrm{Ag} / \mathrm{adhesive} /$ Nome ${ }^{\circledR}$ scrim) was ranked first, and recommended by the FRB as the replacement thermal control material to be installed on HST during SM3. Because of concerns of UV darkening of the adhesive, some of the material 6 samples underwent additional NUV exposure testing at GSFC. Five samples, were exposed for 2000-3000 ESH. No change in solar absorptance was measured. 
Table 6. Final Ranking of HST Thermal Control Candidate Replacement Materials

\begin{tabular}{|c|c|c|}
\hline Rank* & Material & Candidat $\mathrm{e}$ Material \\
\hline 1 & 6 & 5 mil FEP/A 1/adhesive/Nomex ${ }^{\text {scrim }}$ \\
\hline 2 & 3 & $10 \mathrm{mil}$ FEP/Al/adhesive/Nomex ${ }^{(1)}$ scrim \\
\hline 3 & 8 & 5 mil FEP/Al (current HST materia) \\
\hline 4 & 1 & $10 \mathrm{mil} \mathrm{FEP} / \mathrm{Ag} / \mathrm{Inconel} / \mathrm{adhesive} / \mathrm{Nomex}$ scrim \\
\hline 5 & 5 & 5 mil FEP/Ag/Inconel/adhesive/Nomex ${ }^{\text {ig }}$ scrim \\
\hline 6 & 2 & $5 \mathrm{mil} \mathrm{FEP} / \mathrm{Ag} / \mathrm{Inconel} /$ adhesive/fiberglass scrim/adhesive/2 mil Kapton ${ }^{(1)}$ \\
\hline 7 & 7 & OCLI multi-layer oxide UV blocker' 2 mil white Tedlar ${ }^{\text {(I) }}$ \\
\hline 8 & 4 & 5 mil FEP/A l/adhesive/fiberglass sirrim/adhesive/2 mil Kapton ${ }^{13}$ \\
\hline
\end{tabular}

* 1 is the most favorable candidate

\section{Summary and Conclusions}

The outer layer of MLI ( 5 mil Al-FEP) on HST is degrading in the space environment. A HST MLI FRB was chartered to determine the cause of degradation of the FEP, and to recommend a replacement material. The replacement thermal control material was required to meet HST's stringent thermal requirements (end-of-life $\alpha_{s} / \varepsilon \leq 0.28$ ) and to maintain its structural integrity for at least 10 years on-orbit. Candidate replacement materials were chosen through a multiplicative evaluation formula based on nine performance criteria for durability testing. Various sets of candidate replacement materials were exposed to combinations of electron/proton radiation, atomic oxygen, simulated solar flare $\mathrm{x}$-rays, thermal cycling and near ultraviolet radiation at various facilities in order to evaluate their HST on-orbit durability. Two sets of samples (B1 and M2) previously exposed to charged particle radiation were exposed to $x$-rays at l_eRC. One sample set (B1) was also thermal cycled under load at LeRC.

There were very small decreases in mass, and no changes in optical properties, and no change in the original cut, of the candidate materials with simulated solar flare $\mathrm{x}$-ray exposure to 10 year HST fluences (SM3-2010). Small decreases were observed in the tensile properties of companion 5 mil Al-FEP witness samples with x-ray exposure. Generally, there were very small changes in mass with thermal cycling. Thermal cycling caused significant absorptance increases in samples B1.1 (+0.063) and B1.5 $(+0.041)$ which were attributed to an interaction of the Nomex ${ }^{\circledR}$ scrim witt the Sheldahl adhesive upon heating. Samples B1.3 and B1.6, with $\mathrm{Al}$ and Nome ${ }^{\circledR}$ scr ms had absorptance decreases with thermal cycling $(-0.005$ and -0.007 , respectively). Sa mples B 1.2 and B1 .4, with fiberglass scrims and Kapton $\left.{ }^{(}\right)$substrates, tore in half during thermal cycling under load. Sample B1.8 (current HST MLI material) tore about 90 persent of the width during thermal cycling. Tear propagation of the B1 samples was attributed to thermal cycling under a high load. The prior radiation exposures did not appear to have an additional effect on tearing, and no tearing occurred due to mechanical load cycling. The crack morphology of sample B1.8 (5 mil Al-FEP) exposed to radiation then therr al cycled under a high load $(10 \mathrm{lb}$.) 
was ductile in appearance, unlike the glassy crack morphology of the brittle FEP from HST. The crack morphology of radiation exposed scrim containing samples thermal cycled under a low load (constraint loading) at GSFC most closely resembled in-spacepropagated cracks from retrieved HST FEP. Based on $x$-ray and thermal cycling testing at LeRC, samples B1.3 and B1.6 performed the best, with B1.6 having a lower solar absorptance.

Upon completion of testing all candidate samples, the HST MLI FRB met to review the durability results and revote on the candidate materials using the original multiplicative evaluation formula. Material $6\left(5 \mathrm{mil} \mathrm{FEP} / \mathrm{Al} / \mathrm{adhesive} / \mathrm{Nomex}{ }^{\circledR}\right.$ scrim) was ranked first, and recommended by the FRB as the replacement thermal control material to be installed on HST during SM3.

\section{Acknowledgments}

The authors would like to thank the following for their contributions to this program: Tom Stueber of NYMA Inc., and Alice Jalics of Cleveland State University for tensile tests, Kevin Malinowski of Cleveland State University for assistance with thermal cycling, and Dr. Steven Pepper of NASA Lewis Research Center for x-ray spectrum characterization. We would also like to thank Patti Hansen (the HST MLI FRB Chair) and Jackie Townsend of NASA Goddard Space Flight Center, and Joyce Dever of NASA Lewis Research Center for helpful discussions.

\section{References}

1. Hansen, Patricia A., Townsend, Jacqueline A., Yoshikawa Yukio, Castro, David J.. Triolo. Jack J. and Peters. Wanda C.. "Degradation of Hubble Space Telescope Metallized Teflon ${ }^{\text {k: }}$ FEP Thermal Control Materials." Science of Advanced Materials and Process Engineering Series, 43. 1998.

2. Zuby. Thomas M., de Groh. Kim K. \& Smith. Daniela C.. "Degradation of FEP Thermal Control Materials Returned from the Hubble Space Telescope," Proceedings of the Hubble Space Telescope Solar-Array Workshop. Noordwijk. The Netherlands. May 30-31, 1995, ESA WPP-77, pp. 385-402: also NASA TM-104627. December 1995.

3. de Groh, Kim K. \& Smith. Daniela C., "Investigation of Teflon ${ }^{(\mathrm{B})}$ FEP Embrittlement on Spacecraft in Low Earth Orbit." Proceedings of the $7^{\text {th }}$ International Symposium on Materials in Space Environment. Toulouse, France. June 16-20. 1997. ESA SP-399: also NASA TM-113153. 1997.

4. Van Eesbeek, Marc. Levadou. Francois \& Milintchouk, Andrei. "Investigation on FEP from PDM and Harness from HST-SA I," Proceedings of the Hubble Space Telescope Solar-Array Workshop. Noordwijk. The Netherlands, May 30-31. 1995. ESA WPP-77, pp. 403-416.

5. Townsend, Jacqueline A.. Hansen. Patricia A.. Dever. Joyce A. and Triolo, Jack J.. "Analysis of Retrieved Hubble Space Telescope Thermal Control Materials." Science of Advanced Materials and Process Engineering Series. 43. 1998.

6. Dever. Joyce A.. de Groh. Kim K., Townsend, Jacqueline A. and Wang. L. Len. "Mechanical Properties Degradation of Teflon ${ }^{\text {(R) }}$ FEP Returned From the Hubble Space Telescope," Presented at the $36^{\text {th }}$ Aerospace Sciences Meeting \& Exhibit, Reno, NV, January 12-15. 1998. AIAA-98-0895. NASA TM-1998-206618.

7. Dever. Joyce A.. Townsend. Jacqueline A.. Gaier. James R. and Jalics, Alice I., "Synchrotron VUV and Soft $X$-Ray Radiation Effects on Aluminized Teflon "FEP." Science of Advanced Materials and Process Engineering Series. 43. 1998. 
8. Banks, Bruce A., de Groh, Kim K., Stueber, Thomas J. and Si chkar, Edward A., "Ground Laboratory Soft X-Ray Durability Evaluation of Aluminized Teflon ${ }^{\text {E }}$ FEP Thermal Control Insulation." Science of Advanced Materials and Process Engineering Series. 43, 1698.

9. Townsend, Jacqueline A., Hansen. Patricia A., McClendon, Mark W., Dever, Joyce A. and Triolo. Jack J.. "Evaluation and Selection of Replacement Thermal Controi Materials for the Hubble Space Telescope," Science of Advanced Materials and Process Engineering Series, 43. 1998.

10. Henninger, John H., "Solar Absorptance and Thermal Emittance of Some Common Spacecraft ThermalControl Coatings." NASA RP-1121, 1984.

11. Edwards. David L. and Vaughn, Jason A.. "Charged Particle and Atomic Oxygen Exposure of Candidate Replacement Materials for the Hubble Space Telescope." NASA MSFC Test Report. October 15. 1997.

12. The Boeing Company, "Radiation Exposure Testing-HST Thermal Blanket," Boeing Test Report, November, 1997.

13. Milintchouk. Andrei, Van Eesbeek, Marc. Levadou, Francois and Harper, Tim, "Influence of X-Ray Solar Flare Radiation on Degradation of Teflon ${ }^{\text {ik }}$ in Space." J. of Spacecraft and Rockets, Vol. 34, No. 4. July-August 1997. pp. 542-548. 


\begin{tabular}{|c|c|c|c|c|}
\hline \multicolumn{3}{|c|}{ REPORT DOCUMENTATION PAGE } & \multicolumn{2}{|r|}{$\begin{array}{l}\text { Form Approved } \\
\text { OMB No. 0704-0188 }\end{array}$} \\
\hline \multicolumn{5}{|c|}{ 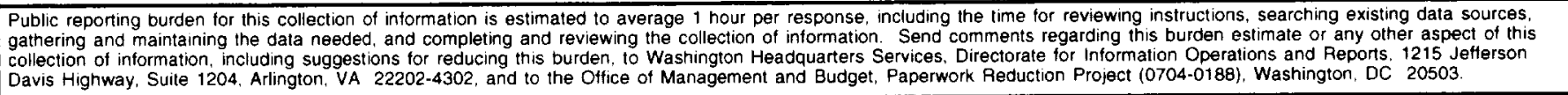 } \\
\hline 1. AGENCY USE ONLY (Leave blank) & $\begin{array}{l}\text { 2. REPORT DATE } \\
\text { December } 1998\end{array}$ & \multicolumn{3}{|c|}{$\begin{array}{l}\text { 3. REPORT TYPE AND DATES COVERED } \\
\text { Technical Memorandum }\end{array}$} \\
\hline \multicolumn{3}{|c|}{$\begin{array}{l}\text { 4. TITLE AND SUBTITLE } \\
\text { Simulated Solar Flare X-Ray and Thermal Cycling Durability Evaluation of } \\
\text { Hubble Space Telescope Thermal Control Candidate Replacement Materials }\end{array}$} & \multicolumn{2}{|c|}{ 5. FUNDING NUMBERS } \\
\hline \multicolumn{3}{|c|}{$\begin{array}{l}\text { 6. AUTHOR(S) } \\
\text { Kim K. de Groh, Bruce A. Banks, Edward A. Sechkar, and David A. Scheiman }\end{array}$} & \multicolumn{2}{|c|}{$\mathrm{WU}-6.32-1 \mathrm{~A}-1 \mathrm{E}-00$} \\
\hline \multicolumn{3}{|c|}{$\begin{array}{l}\text { 7. PERFORMING ORGANIZATION NAME(S) AND ADDRESS(ES) } \\
\text { National Aeronautics and Space Administration } \\
\text { Lewis Research Center } \\
\text { Cleveland, Ohio } 44135-3191\end{array}$} & \multicolumn{2}{|c|}{$E-11184$} \\
\hline \multicolumn{3}{|c|}{ 9. SPONSORING/MONITORING AGENCY NAME(S) AND ADDRESS(ES) } & 10. SP & $\begin{array}{l}\text { VSOAING/MONITORING } \\
\text { NCY REPORT NUMBER } \\
\text { SA TM-1998-207426 }\end{array}$ \\
\hline \multicolumn{5}{|c|}{$\begin{array}{l}\text { 11. SUPPLEMENTARY NOTES } \\
\text { Prepared for the Fourth International Space Conference on Protection of Materials and Structures from the LEO Space } \\
\text { Environment sponsored by the University of Toronto and the Institute for Aerospace Studies, Toronto, Canada. April 23- } \\
\text { 24, 1998. Kim K. de Groh and Bruce A. Banks, NASA Lewis Research Center; Edward A. Sechkar and David A. } \\
\text { Scheiman, NYMA, Inc., } 2001 \text { Aerospace Parkway, Brook Park, Ohio 44142. Responsible person, Kim K. de Groh, } \\
\text { organization code } 5480,(216) 433-2297 \text {. }\end{array}$} \\
\hline \multicolumn{3}{|c|}{$\begin{array}{l}\text { 12a. DISTRIBUTION/AVAILABILITY STATEMENT } \\
\text { Unclassified - Unlimited } \\
\text { Subject Categories: } 18,92 \text {, and } 27 \quad \text { Distribution: Nonstandard } \\
\text { This publication is available from the NASA Center for AeroSpace Information, (301) 621-0390. }\end{array}$} & \multicolumn{2}{|c|}{ 12b. DISTRIBUTION CODE } \\
\hline \multicolumn{5}{|c|}{$\begin{array}{l}\text { 13. ABSTRACT (Maximum 200 words) } \\
\text { During the Hubble Space Telescope (HST) second servicing mission (SM2), astronauts noticed that the multilayer } \\
\text { insulation (MLI) covering the telescope was damaged. Large pieces of the outer layer of MLI (aluminized Teflon } \\
\text { fluorinated ethylene propylene (Al-FEP)) were torn in several locations around the telescope. A piece of curled up AI- } \\
\text { FEP was retrieved by the astronauts and was found to be severely embrittled, as witnessed by ground testing. Goddard } \\
\text { Space Flight Center (GSFC) organized a HST MLI Failure Review Board (FRB) to determine the damage mechanism of } \\
\text { FEP in the HST environment, and to recommend replacement insulation material to be installed on HST during the third } \\
\text { servicing mission (SM3) in 1999. Candidate thermal control replacement materials were chosen by the FRB and tested } \\
\text { for environmental durability under various exposures and durations. This paper describes durability testing of candidate } \\
\text { materials which were exposed to charged particle radiation, simulated solar flare x-ray radiation and thermal cycling } \\
\text { under load. Samples were evaluated for changes in solar absorptance and tear resistance. Descriptions of environmental } \\
\text { exposures and durability evaluations of these materials are presented. }\end{array}$} \\
\hline \multirow{2}{*}{\multicolumn{4}{|c|}{$\begin{array}{l}\text { 14. SUBJECT TERMS } \\
\text { Hubble space telescope: Thermal control coatings: Solar } x \text {-rays; Absorptance: Teflon; } \\
\text { Thermal cycling: Space environment simulation: Soft } x \text {-rays }\end{array}$}} & $\begin{array}{c}\text { 15. NUMBER OF PAGES } \\
32\end{array}$ \\
\hline & & & & \begin{tabular}{r|r|}
32 \\
16. PAICE CODE \\
$\mathrm{A} 03$ \\
\end{tabular} \\
\hline $\begin{array}{l}\text { 17. SECURITY CLASSIFICATION } \\
\text { OF REPORT } \\
\text { Unclassified }\end{array}$ & $\begin{array}{l}\text { 18. SECURITY CLASSIFICATION } \\
\text { OF THIS PAGE }\end{array}$ & $\begin{array}{l}\text { 19. SECURITY CLASSIFI } \\
\text { OF ABSTRACT }\end{array}$ & & 20. LIMITATION OF ABSTRACT \\
\hline Unclassified & Unclassified & Unclassifiec & & \\
\hline
\end{tabular}


